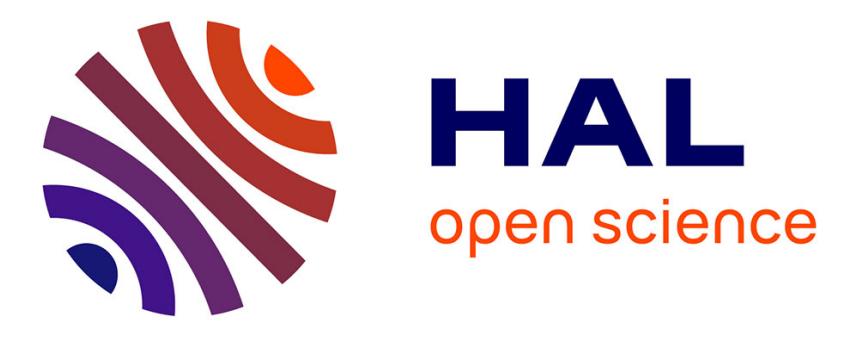

\title{
Thermoelectric materials for space applications
}

Christophe Candolfi, Soufiane El Oualid, Dorra Ibrahim, Shantanu Misra, Oussama El Hamouli, Adèle Léon, Anne Dauscher, Philippe Masschelein, Philippe Gall, Patrick Gougeon, et al.

\section{- To cite this version:}

Christophe Candolfi, Soufiane El Oualid, Dorra Ibrahim, Shantanu Misra, Oussama El Hamouli, et al. Thermoelectric materials for space applications. CEAS Space Journal, 2021, 13 (3), pp.325-340. 10.1007/s12567-021-00351-x . hal-03190535

\section{HAL Id: hal-03190535 https://hal.univ-lorraine.fr/hal-03190535}

Submitted on 18 May 2021

HAL is a multi-disciplinary open access archive for the deposit and dissemination of scientific research documents, whether they are published or not. The documents may come from teaching and research institutions in France or abroad, or from public or private research centers.
L'archive ouverte pluridisciplinaire HAL, est destinée au dépôt et à la diffusion de documents scientifiques de niveau recherche, publiés ou non, émanant des établissements d'enseignement et de recherche français ou étrangers, des laboratoires publics ou privés. 


\section{Thermoelectric materials for space applications}

Christophe Candolfi1 ${ }^{1, *}$, Soufiane El Oualid ${ }^{1}$, Dorra Ibrahim ${ }^{1}$, Shantanu Misra ${ }^{1}$, Oussama El Hamouli $^{1}$, Adèle Léon ${ }^{1}$, Anne Dauscher ${ }^{1}$, Philippe Masschelein ${ }^{1}$, Philippe Gall ${ }^{2}$, Patrick Gougeon $^{2}$, Christopher Semprimoschnig ${ }^{3, \dagger}$, Bertrand Lenoir ${ }^{1, *}$

${ }^{1}$ Institut Jean Lamour, UMR 7198 CNRS - Université de Lorraine, Campus ARTEM, 2 allée André Guinier, BP 50840, 54011 Nancy, France

${ }^{2}$ Institut des Sciences Chimiques de Rennes, UMR 6226 CNRS - Université de Rennes 1 INSA de Rennes - Ecole Nationale Supérieure de Chimie de Rennes, 11 allée de Beaulieu, CS 50837, 35708 Rennes Cedex, France

${ }^{3}$ European Space Agency, ESTEC, P.O. Box 299, Keplerlaan 1, 2200 AG Noordwijk, The Netherlands

*Corresponding Authors: $\quad \underline{\text { christophe.candolfi@,univ-lorraine.fr; }} \quad \underline{\text { bertrand.lenoir@,univ- }}$ $\underline{\text { lorraine.fr }}$

${ }^{\dagger}$ C. S. passed away in 2020

\section{Abstract}

Solid-state energy conversion through thermoelectric effects remains the technology of choice for space applications for which, their low energy conversion efficiency is largely outweighed by the reliability and technical requirements of the mission. Radioisotope thermoelectric generators (RTGs) enables the direct conversion of the heat released by nuclear fuel into the electrical power required to energize the scientific instruments. The optimization of the conversion efficiency is intimately connected to the performances of the thermoelectric 
materials integrated which are governed by the transport properties of these materials. Recent advances in the design of highly-efficient thermoelectric materials raise interesting prospects to further enhance the performances of RTGs for future exploratory missions in the Solar system. Here, we briefly review the knowledge acquired over the last years on several families of thermoelectric materials, the performances of which are close or even higher than those conventionally used in RTGs to date. Issues that remain to be solved are further discussed.

Keywords: Thermoelectric, RTG, Semiconductors, Space mission

\section{Declarations}

\section{Funding}

European Space Agency (ESA/ESTEC)

\section{Conflicts of Interest}

The authors declare no competing financial interest.

\section{Availability of data and material}

Not applicable

\section{Code availability}

Not applicable 


\section{Introduction}

Thermoelectric materials provide an elegant and versatile way to convert a temperature difference into electrical power (Seebeck effect) or vice versa (Peltier effect) [1-3]. Thermoelectric generators (TEGs, see Fig. 1), in which these materials are integrated, possess important advantages over other energy conversion technologies. In particular, the TEGs does not exhibit any moving parts and are thus noise- and vibration-free during operation, conferring high mechanical reliability with low maintenance levels and hence, long lifetime. These properties make TEGs fully autonomous and particularly well-suited for operating in isolated areas on Earth and in the extreme environments of space and other planetary surfaces. These TEGs can be either scaled up or downsized, offering a high adaptability for a plethora of applications ranging from waste-heat recovery in various industrial processes to the powering of autonomous micro-sensors for Internet-of-things (IoT) applications [4-8]. 
a)

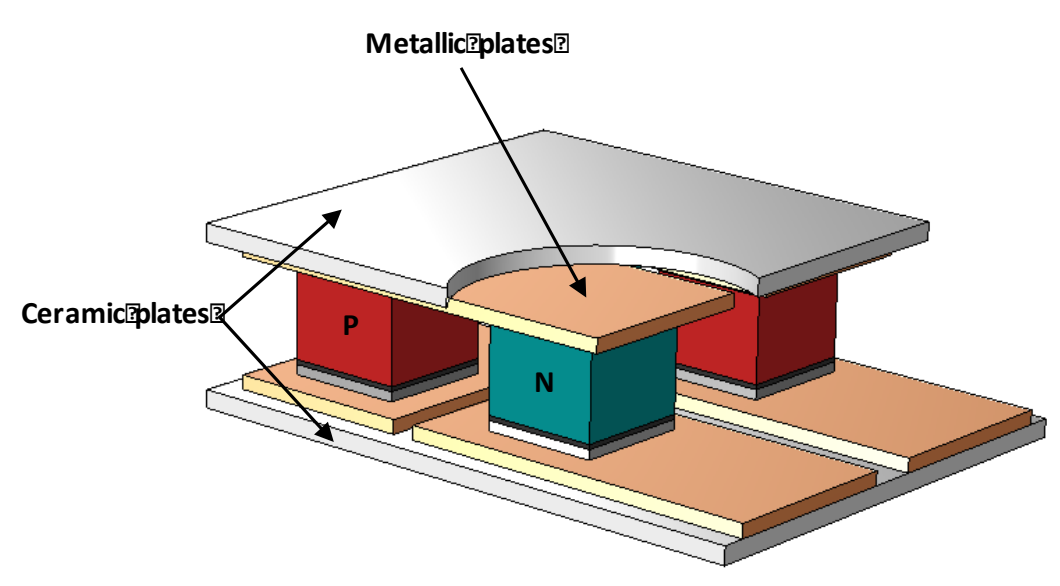

c)

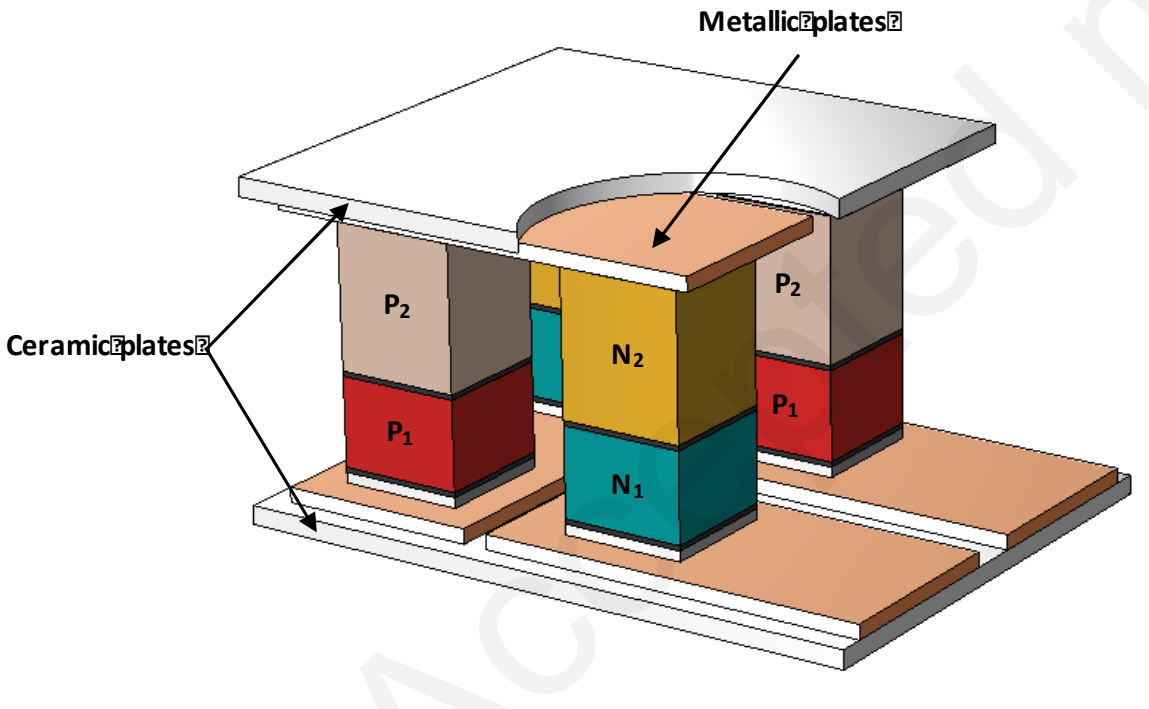

b)

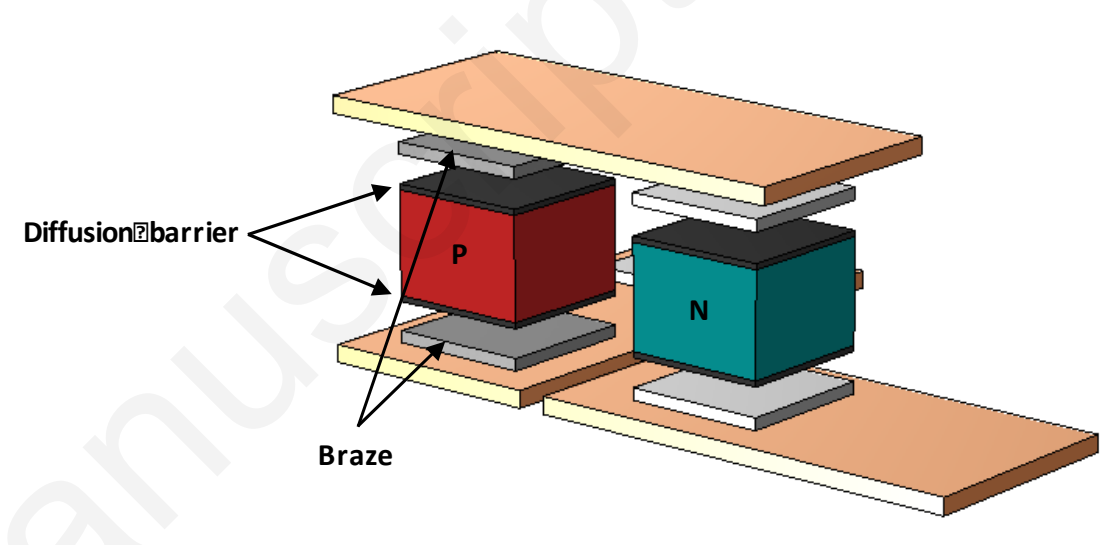

d)

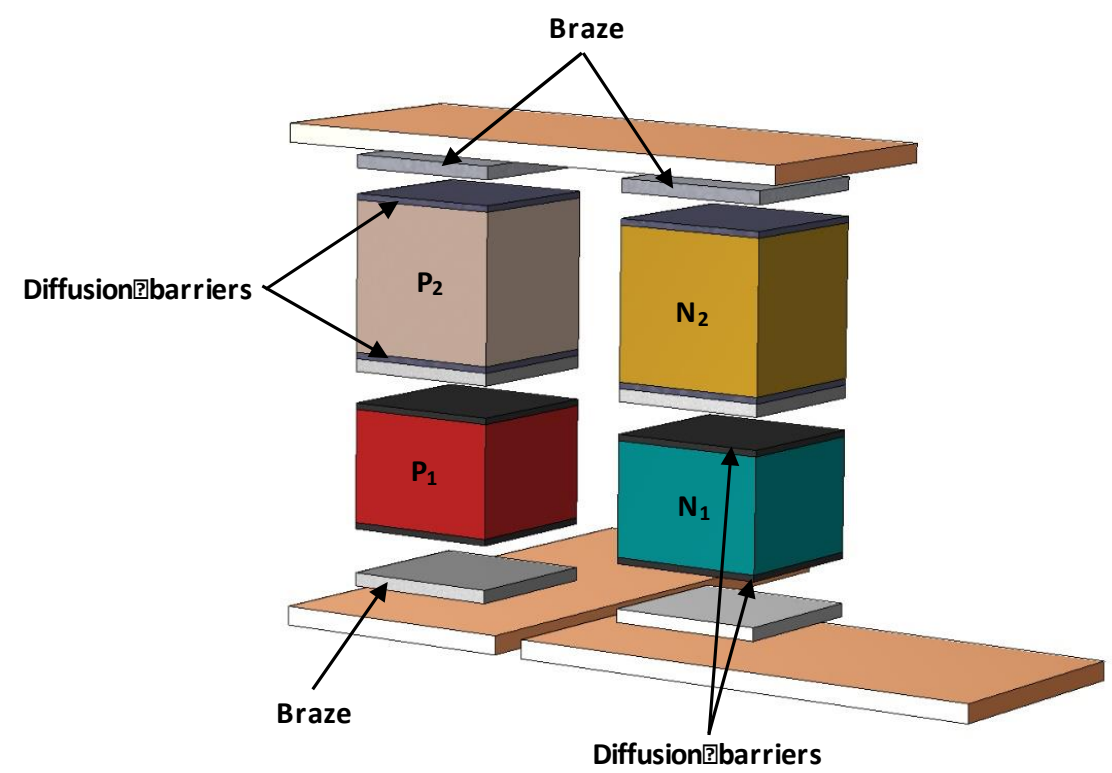


Fig. 1. a) Conventional " $\pi$-shape" design of a thermoelectric device. The $n$-and $p$-type thermoelectric compounds are connected electrically in series and thermally in parallel via electrical interconnections (metallic plates) usually made of pure copper. The number of $n$ - $p$ couples can be increased depending on the desired output power. This assembly is sandwiched by two ceramic plates. b) Both the $n$ - and $p$-type legs are brazed on the metallic plates to ensure low electrical contact resistances (too high contact resistances are detrimental to high output performances of the device). An additional diffusion barrier is inserted between the thermoelectric compounds and the braze to avoid interdiffusion of the elements triggered by the high temperatures the materials are subjected to. c) Illustration of a thermoelectric device with segmented legs composed, as an example, of two different thermoelectric materials. Each $n$ - and $p$-type material is carefully chosen and optimized in order to achieve its maximum $Z T$ value in the temperature range that corresponds to the thermal gradient it is subjected to. This strategy helps to maintain high average $Z T$ values for both legs and hence, high conversion efficiency. d) However, the possible interdiffusion of the elements at each interface are two key issues that must be properly solved in order to make this solution technically viable. For this reason, the thermoelectric materials are sandwiched by diffusion barriers. 
For space applications, radioisotope thermoelectric generators (RTGs) are considered as the best solution for planetary and deep-space missions for which the use of solar cells or alternative technologies are challenging. A RTG directly converts the heat released by the nuclear decay of radioactive isotopes (Fig. 2) into electricity [1]. While ${ }^{238} \mathrm{Pu}$ has been the nuclide of choice used in American and Russian RTGs, European RTGs utilizing the candidate isotope ${ }^{241} \mathrm{Am}$ are currently being developed as part of a ESA program since $2009[1,9]$. Historically, several deep-space probes, spacecrafts (Pioneer 10 and 11, Voyager 1 and 2, Ulysses, Galileo, Cassini, New Horizons...) and the Mars rover Curiosity were successfully powered by RTGs. Voyager 1 and 2, both launched in 1977, are prominent examples that demonstrate the high reliability and resistance to space radiations of RTGs over very long periods of time. As an alternative solution to RTGs, solar thermoelectric generators (STG) convert the heat from the Sun. STGs have been proposed for space missions flying close to the Sun where the high temperature of the environment prevents the use of conventional solar cells [10]. However, while numerical results suggested that the STG concept could be a promising alternative, no technical development were subsequently undertaken [10,11]. 
a)

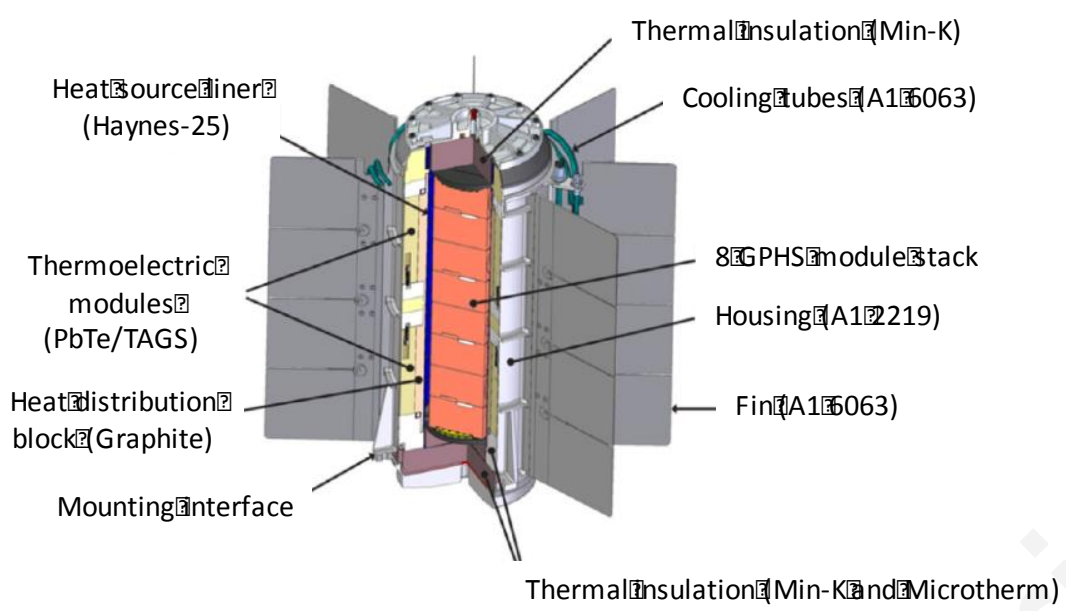

b)

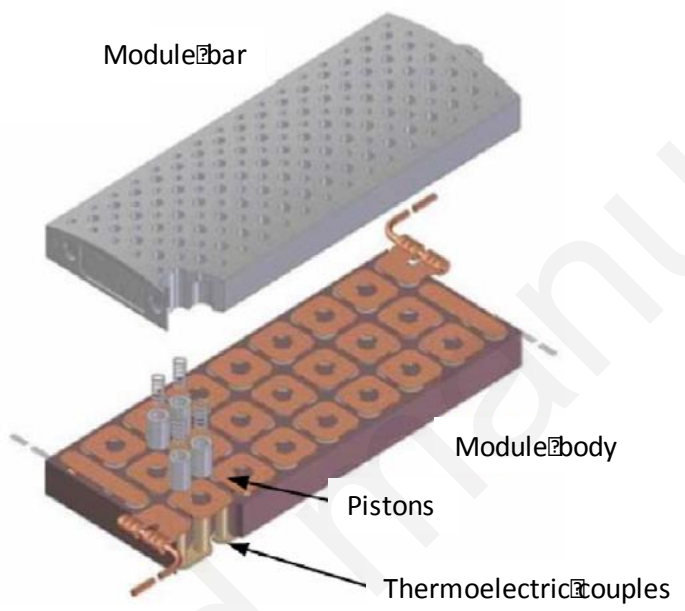

Fig. 2. a) General design of a radioisotope thermoelectric generator (RTG) $[12,13]$. b) Thermoelectric module integrated into the RTG.

One of the major drawback of RTGs is their low conversion efficiency $\eta_{R T G}$, which remains on the order of $6-10 \%[1,14-16]$, although various non-conventional designs of the thermoelectric legs or of the TEG itself have been studied. $\eta_{R T G}$ is governed by both the temperature gradient the thermoelectric materials are subjected to and a material-dependent parameter called the dimensionless thermoelectric figure of merit ZT [1-3]. ZT is defined at the absolute temperature $T$ by the relation $Z T=\alpha^{2} T / \rho \kappa$ where $\alpha$ is the thermopower (or Seebeck coefficient), $\rho$ is the electrical resistivity and $\kappa$ is the total thermal conductivity which can be further decomposed as the sum of the lattice $\kappa_{p h}$ and electronic $\kappa_{e}$ contributions. Achieving 
high conversion efficiency requires maximizing the $Z T$ values at the operating temperature, which necessitates high $\alpha$ values to generate a sizeable thermoelectric effect, low $\rho$ values to minimize the Joule effect and low $\kappa$ values to maintain the thermal gradient between the hot and cold side of the device. Typical peak $Z T$ values of materials integrated in RTGs are around unity, reached at various temperatures ranging from 600 up to $1200 \mathrm{~K}$ (see below) [1,3]. Of particular relevance for practical applications, the $Z T$ values should also remain high over an extended temperature window, rather than merely peaking in a narrow temperature range. This characteristic is quantified through the average $Z T$ value, determined by integrating over the temperature gradient undergone by the TE materials.

While seemingly simple, realizing these three above-mentioned requirements in a single material is extremely challenging. One of the main difficulties is related to the interdependence of the three transport coefficients via the charge carrier concentration, making the optimization of one of these parameters independently from the others practically impossible. In addition, achieving extremely low values of $\kappa_{p h}$ is usually obtained in highly-disordered or amorphous compounds [1,3], the nature of which prevents high mobility of the charge carriers, necessary to maintain $\rho$ to low values, from being achieved. For these reasons, a subtle balance between high power factor $\alpha^{2} / \rho$ and low $\kappa_{p h}$ must be fulfilled. The best compromise is usually obtained in highly-doped semiconductors that crystallize with a complex crystal structure $[1,3]$. Over the last decades, several strategies to either improve $\alpha^{2} / \rho$, such as band convergence or resonant levels (Fig. 3) [17-26], or lower $\kappa_{p h}$, for instance via the formation of solid solutions [3,27] or by considering open, "cage-like" structures such as skutterudites or clathrates [28-39], have been devised to enhance the $Z T$ values. In parallel, significant efforts have been devoted to integrate the novel, highly-efficient thermoelectric materials that have been designed worldwide, leading to significant advances in the output performances of TEGs $[1,14-16]$. 


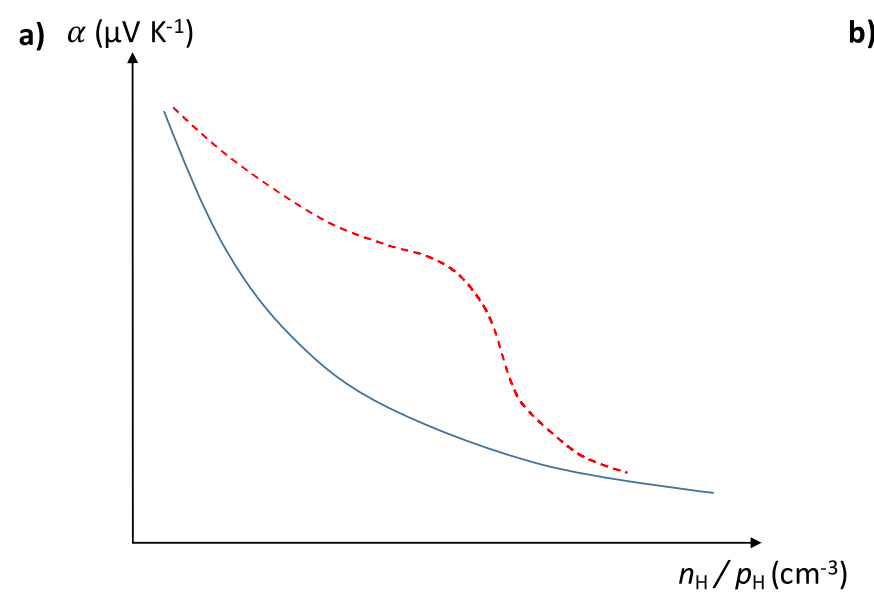

b)

Fig. 3. a) Schematic representation of the variations in the thermopower $\alpha$ (in absolute value for $n$-type compounds) as a function of the carrier concentration $n_{H} / p_{H}$ called the IoffePisarenko curve. For conventional impurities (solid blue curve), $\alpha$ monotonically decreases with increasing the carrier concentration. For specific impurities inducing the formation of a resonant level, that is, a local distortion of the valence or conduction bands, a clear departure from the expected trend is observed indicating that higher $\alpha$ values could be obtained for similar carrier concentrations. b) Schematic view of band convergence in the illustrative case of conduction bands (a similar mechanism occurs for the valence bands). Increasing $x$, which can stand for the concentration of a substituting element or a compound in the case of solid solutions, results in a shift of the two conduction band minima that eventually become degenerate at a specific concentration for which the convergence of the two bands is thus realized. This convergence enables to increase $\alpha$ due to the higher number of valleys $N_{V}$ that directly impact the density-of-states effective mass $m_{D O S}^{*}\left(\alpha \propto m_{D O S}^{*}=N_{V}^{2 / 3} m_{b}^{*}\right.$ where $m_{b}^{*}$ is the band effective mass).

The present review focuses on state-of-the-art as well as novel thermoelectric materials for space applications and is primarily dedicated to readers unfamiliar with thermoelectric materials. Readers particularly interested in deepening their knowledge on the chemistry and 
physics of the various novel families of thermoelectric materials currently studied or on other applications of thermoelectricity can find more detailed descriptions in several recent excellent reviews $[1,12,40-42]$. Our intention herein is to provide a general, yet brief overview of stateof-the-art thermoelectric materials, followed by an introduction of several novel families, some of them developed by the present authors during collaborative projects with the European Space Research and Technology Centre (ESTEC), that are currently being integrated into the nextgeneration RTGs or that might replace the currently-used compounds in future space missions. Their main physical properties and advantages compared to other thermoelectric compounds will be discussed before highlighting the challenges that remain to be overcome.

\section{State-of-the-art thermoelectric materials in RTGs}

Historically, chalcogenide semiconductors have been the materials of choice for thermoelectric applications in power generation $[1,43,44]$. Their rich, yet complex, chemistry offers numerous possibilities to adjust their thermoelectric properties, that made them prime candidates during the dawn of RTG development in the $50 \mathrm{~s}$ and $60 \mathrm{~s}$. In order of increasing temperature, bismuth telluride $\mathrm{Bi}_{2} \mathrm{Te}_{3}$-based alloys, lead telluride $\mathrm{PbTe}$, TAGS composed of tellurium, antimony, germanium and silver, and silicon-germanium solid solution $\mathrm{Si}_{1-x} \mathrm{Ge}_{x}$ have all been used in thermoelectric devices [1], should it be for cooling $\left(\mathrm{Bi}_{2} \mathrm{Te}_{3}\right)$ or power generation applications. Except for $\mathrm{Bi}_{2} \mathrm{Te}_{3}$, all the other materials have been successfully integrated in RTGs and launched in space. This sole exception of $\mathrm{Bi}_{2} \mathrm{Te}_{3}$-based alloys may nevertheless change in the near future, with these materials becoming the active part of RTGs currently developed by ESA [9]. Using ${ }^{241} \mathrm{Am}$ as the fuel source results in lower temperatures at the hot side compared to ${ }^{238} \mathrm{Pu}$-based sources, making the well-mastered $\mathrm{Bi}_{2} \mathrm{Te}_{3}$-based $\mathrm{TE}$ modules a viable strategy to power European deep-space probes from the mid 2020s onwards. 
$\mathrm{Bi}_{2} \mathrm{Te}_{3}$-based alloys exhibit peak $Z T$ values near 1.0 around room temperature (Fig. 4), and still remain to date the best alloys for cooling applications [1,45]. In contrast, lead telluridebased materials have their maximum performances achieved between 600 and $900 \mathrm{~K}[1,46]$, while $\mathrm{Si}_{1-x} \mathrm{Ge}_{x}$ can operate at higher temperatures of up to $1275 \mathrm{~K}[1,47]$. PbTe-based compounds exhibit all the desirable characteristics a good thermoelectric material should possess, that is, heavily-doped semiconducting-like electronic properties, corresponding to carrier concentrations ranging between $10^{19}$ and $10^{21} \mathrm{~cm}^{-3}$ at $300 \mathrm{~K}[1,46]$, combined with a poor ability to transport heat despite their simple rocksalt cubic crystal structure $[1,48,49]$. Numerous elements can be used as dopants, offering the possibility to achieve both $n$ - and $p$ type electrical conduction $[1,46]$. This peculiarity is important regarding their integration in RTGs. Achieving similar transport properties of the $n$ - and $p$-type thermoelectric legs result in equivalent surface areas, which helps to limit the thermomechanical stresses undergone by the legs and thus, to enhance the lifetime of the module [1].

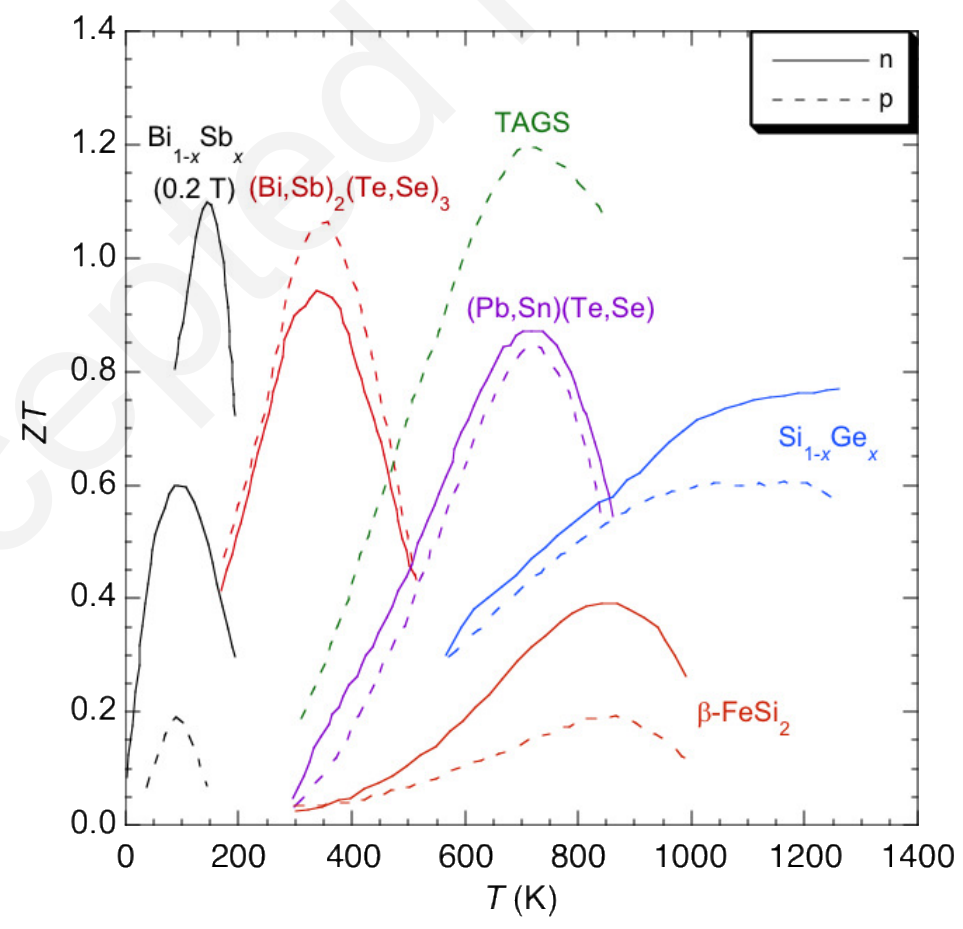

Fig. 4. Temperature dependence of the dimensionless thermoelectric figure of merit $Z T$ of various state-of-the-art $n$-type and $p$-type thermoelectric materials [1,45-52]. 
All these alloys nevertheless exhibit $Z T$ values close to unity in their optimum temperature range, which limit the conversion efficiency of the RTG. Although some progress in the optimization of these alloys have been achieved over the last two decades through band structure engineering or nanostructuration $[1,18,46,53]$, the thermal stability of nanostructured materials over long periods of time remains an important issue. For this reason, the output performances of RTGs have not yet benefited from these advances. Because thermoelectric materials often exhibit a maximum $Z T$ in a limited temperature range, seeking for materials that exhibit high average $Z T$ values over an extended temperature range is of prime importance. As we will see below, the thermal stability of optimized thermoelectric materials should be also ensured to be potential candidates for integration in RTGs.

\section{Novel thermoelectric materials for RTGs}

\section{1 $\mathrm{Sn} X(X=$ Se and Te $)$ compounds for mid-temperature range}

Significant efforts are currently being devoted to the identification, synthesis and optimization of novel materials with superior thermoelectric properties that could replace the state-of-the-art $n$-type and $p$-type thermoelectric compounds that have been used in RTGs for decades (Fig. 5). In addition to $p$-type $\mathrm{Yb}_{14} \mathrm{MnSb}_{11}$ [54] and $n$-type La3-x $\mathrm{Te}_{4}$ [55] Zintl phases and both $n$ - and $p$-type skutterudites [29-31], the physical properties of which will be discussed in more detail below, $n$ - and $p$-type Half-Heuslers are interesting candidates for operating near $1200 \mathrm{~K}$ due to their excellent thermoelectric performances and their good thermal stability in this temperature range. While efforts are currently being devoted to integrate these materials in thermoelectric devices for terrestrial applications in power generation [56], these compounds have however not yet been considered as alternative materials for $\mathrm{Si}_{1-x} \mathrm{Ge}_{x}$ alloys in RTGs. 
a)

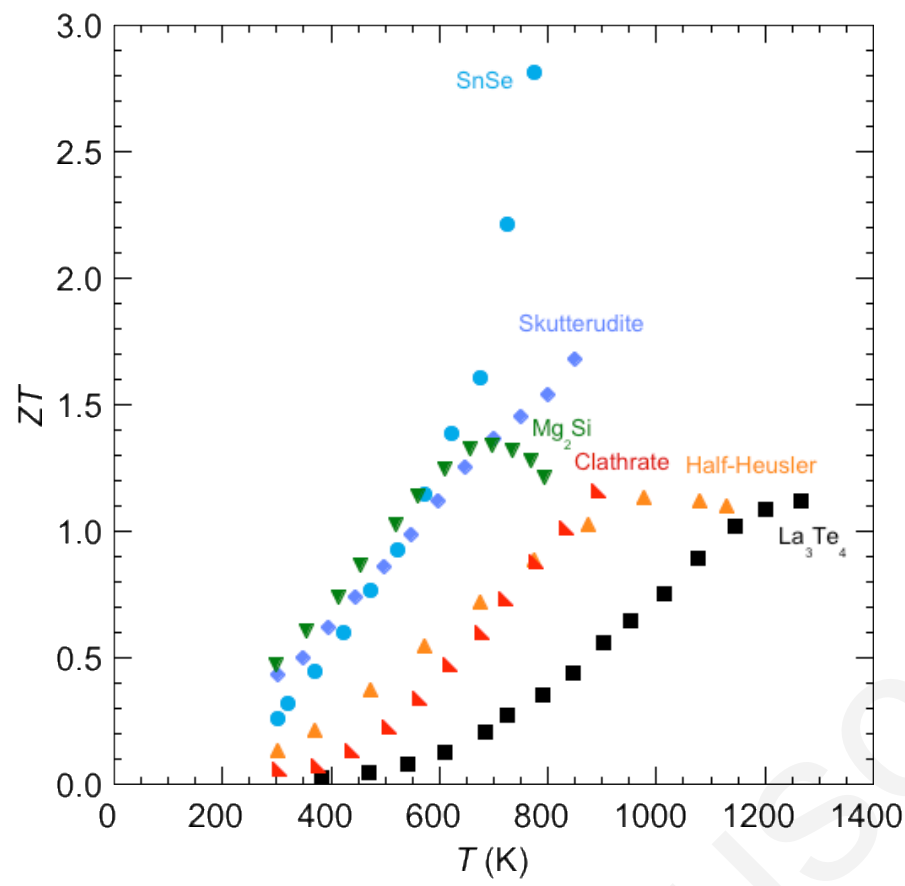

b)

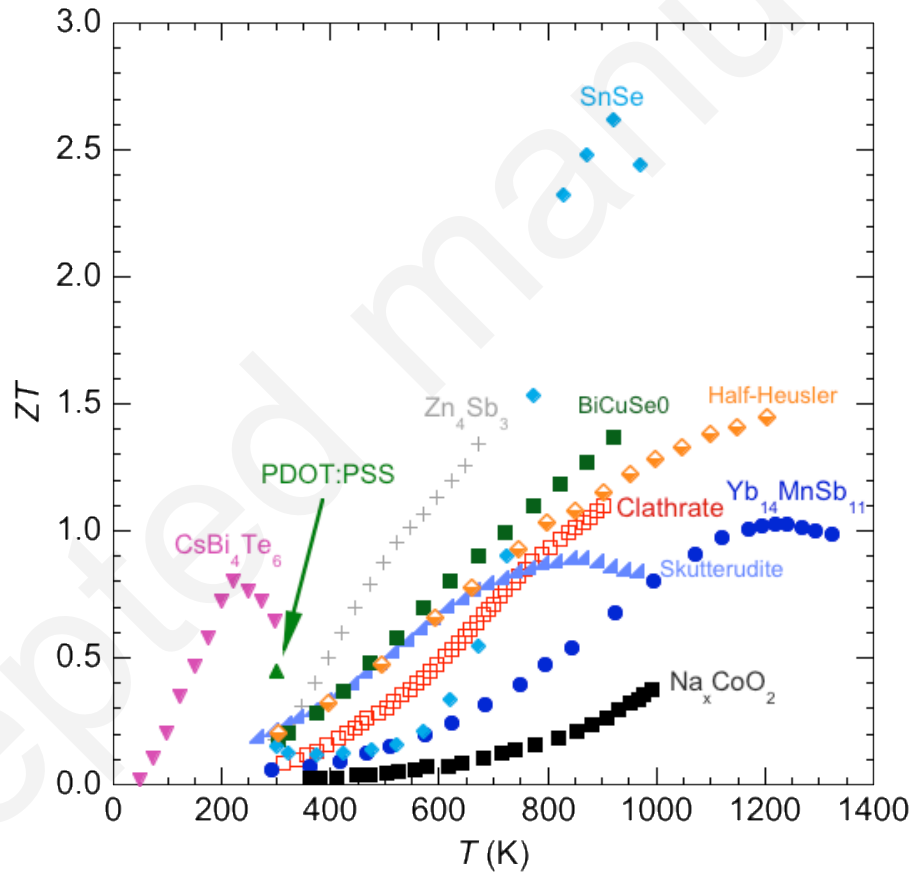

Fig. 5. Temperature dependence of the dimensionless thermoelectric figure of merit $Z T$ of selected novel families of a) $n$-type and b) $p$-type thermoelectric materials that have emerged over the last two decades [1,29-31,54-65].

In the mid temperature range $(600-800 \mathrm{~K}), \operatorname{Sn} X(X=\mathrm{Se}$ and Te $)$ binary semiconduc tors have been recently considered as possible alternatives to PbTe-based alloys [56,57,66-79]. In particular, both $\mathrm{SnSe}$ and $\mathrm{SnTe}$ have been extensively investigated due to their favorable 
electronic properties, low lattice thermal conductivity and the high number of elements that can act as effective hole-like or electron-like dopants [56,57,66-79]. While being overlooked for long in comparison to PbTe-based alloys due to its non-cubic, orthorhombic crystal structure, SnSe has stirred up strong interest over the last years after the announcement of record-breaking $Z T$ values of up to 2.6 at $923 \mathrm{~K}$ in pristine single crystals [56,57]. Although subsequent detailed reinvestigations of the transport properties of single-crystalline and polycrystalline specimens seriously called into question these claims [56,57,66-76], several studies have nevertheless demonstrated that $\mathrm{SnSe}$ is both $n$ - and $p$-type dopable with optimum $Z T$ values of 1.2 and 1.0 near $800 \mathrm{~K}$, respectively [80-82]. These high $Z T$ values stem from the electronic band structure that favors high thermopower values and the strong anharmonic behavior of the lattice resulting in very low lattice thermal conductivity values on the order of $0.5 \mathrm{~W} \mathrm{~m}^{-1} \mathrm{~K}^{-1}$ at $800 \mathrm{~K}$ [83-87].

Compared to SnSe, SnTe crystallizes with a cubic rocksalt crystal structure giving rise to isotropic transport properties [70-79]. Being isomorphous with $\mathrm{PbTe}, \mathrm{SnTe}$ also features a very similar valence band structure mainly comprising two maxima (Fig. 6) [88,89], both of which playing a key role in governing the transport properties at high temperatures [70-79]. In contrast to $\mathrm{PbTe}$ that can be made both $n$ - and $p$-type, SnTe inherently shows off-stoichiometry due to Sn vacancies [70,71]. Because each vacancy acts as a double acceptor, all SnTe samples are heavily hole-doped, with a hole concentration varying between $10^{19}$ and $10^{21} \mathrm{~cm}^{-3}$ depending on the vacancy concentration [70,71,77-79], explaining why an $n$-type electrical conduction has never been achieved so far. Both the details of the synthesis method as well as various dopants on either the $\mathrm{Sn}$ or Te sites can tune the vacancy concentration and hence [70-79], the thermoelectric properties, giving rise to a maximum $Z T$ value of 0.6 at $800 \mathrm{~K}$ in non-substituted SnTe samples [72-79]. 
a)

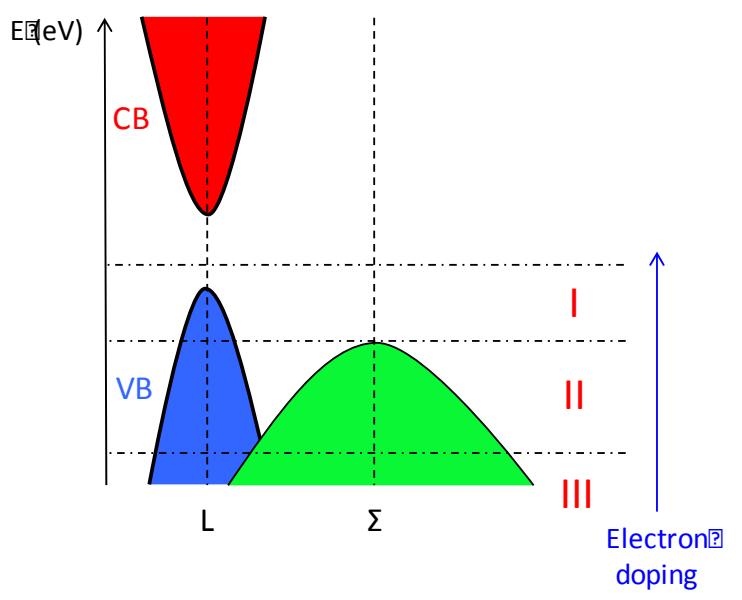

b)

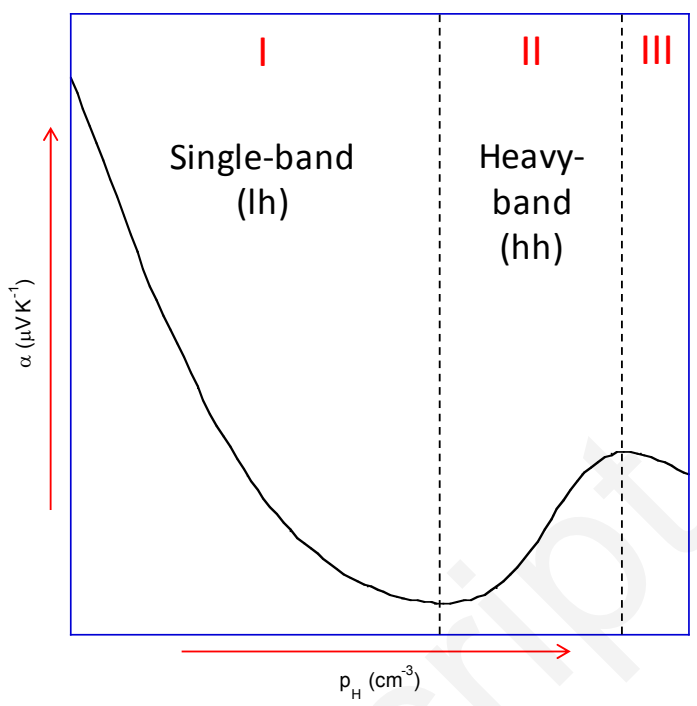

Fig. 6. a) Schematic view of the electronic band structure of SnTe $[88,89]$. The valence band (VB) is separated from the conduction band (CB) by a direct band gap. The VBs are mainly composed of two maxima at the $\mathrm{L}$ and $\Sigma$ points of the Brillouin zone, giving rise to light holes (L) and heavy holes $(\Sigma)$. This two-valence band structure has direct consequences on the evolution of the thermopower $\alpha$ as a function of the hole concentration $p_{H}$ shown in $\mathrm{b}$ ). This curve, called a Ioffe-Pisarenko curve, exhibits a hump in the region II due to the contribution of the second, heavy-hole valence band. Thermoelectric compounds for which a single band governs their transport properties show a smooth decrease in $\alpha$ with increasing $p_{H}$ (or $n_{H}$ for n-type compounds).

Several doping elements on the $\mathrm{Sn}$ site, such as $\mathrm{Mn}$ or $\mathrm{Hg}$, have been shown to promote the convergence of the two valence-band maxima [72,73], the energy offset of which is around $0.35 \mathrm{eV}$ at $300 \mathrm{~K}$ in pristine $\mathrm{SnTe}$ [70-79]. Due to this band-shape-modification effect, the thermopower values are strongly enhanced, yielding large power factors in samples with optimized composition $[90,91]$. Combined with reasonably low lattice thermal conductivity values on the order of $2-3 \mathrm{~W} \mathrm{~m}^{-1} \mathrm{~K}^{-1}$ at $800 \mathrm{~K}, Z T$ values between 0.8 and 1.2 could be obtained using various dopants $[90,91]$. Another effective strategy to enhance the power factor of SnTebased compounds is related to the partial substitution of In for Sn, which gives rise to the 
formation of a resonant level (RL), that is, a local distortion of the valence bands arising from the hybridization of the In states with those of the host framework [24,92]. The broad hump that emerges in the electronic density of states (DOS) results in higher thermopower values when the chemical potential resides in this enhanced DOS, providing an elegant mean to further improve the $Z T$ values. Furthermore, because the distortion of the DOS is nearly temperatureindependent, the presence of a RL tends to lead to higher average $Z T$ values, that is, high $Z T$ values are obtained over a broader temperature window, an important aspect for practical applications [24].

Additional optimization of the $Z T$ values of SnTe-based compounds were achieved by combining elements that induce favorable modification of the valence band structure with single elements or binaries that give rise to the formation of nano-precipitates embedded in the matrix $[90,91]$. Such peculiar microstructure engineering at both the nano and mesoscale is expected to strongly disrupt the propagation of acoustic phonons, thereby significantly lowering the ability of the compound to transport heat. This overall approach yielded very high $Z T$ values of up to 1.6 at $800 \mathrm{~K}[90,91,93]$, further showing that these compounds could be a viable solution to replace $p$-type PbTe and TAGS in RTGs. However, further detailed studies on the thermal stability of these nanostructured compounds should be performed to determine whether long-term stability at high temperatures is achieved.

\subsection{Skutterudites}

Among the novel thermoelectric materials candidates that emerge over the last two decades, skutterudites, named after the Norwegian small mining town Skutterud where a CoAs3-based mineral has been identified in 1845 , are probably the closest to a qualification into an advanced RTG. They represent a broad family of semiconducting compounds comprising eleven binary compounds and numerous ternary and quaternary compositions [29,30]. Their 
large chemical flexibility, which can be in most cases rationalized by the Zintl-Klemm formalism (see below), offers an excellent playground for tuning their electronic and thermal properties, giving rise to various electronic and magnetic phenomena including superconductivity, heavy-fermion behavior and high thermoelectric performances near $800 \mathrm{~K}$ $[29,30,94-96]$.

Binary skutterudites possess a general chemical formula written as $M X_{3}$ where $M$ is a transition metal from group IX (Co, Rh or Ir) and $X$ is a pnictogen from group V (P, As or $\mathrm{Sb})$. These compounds crystallize with a cubic unit cell, described in the space group $\operatorname{Im} \overline{3}$, in which the $M$ atoms form a simple cubic lattice while the $X$ atoms form quasi-squared planar complexes $X_{4}$ inserted in the cubes and orientated along the three crystallographic directions [100], [010] and [001] (Fig. 7).

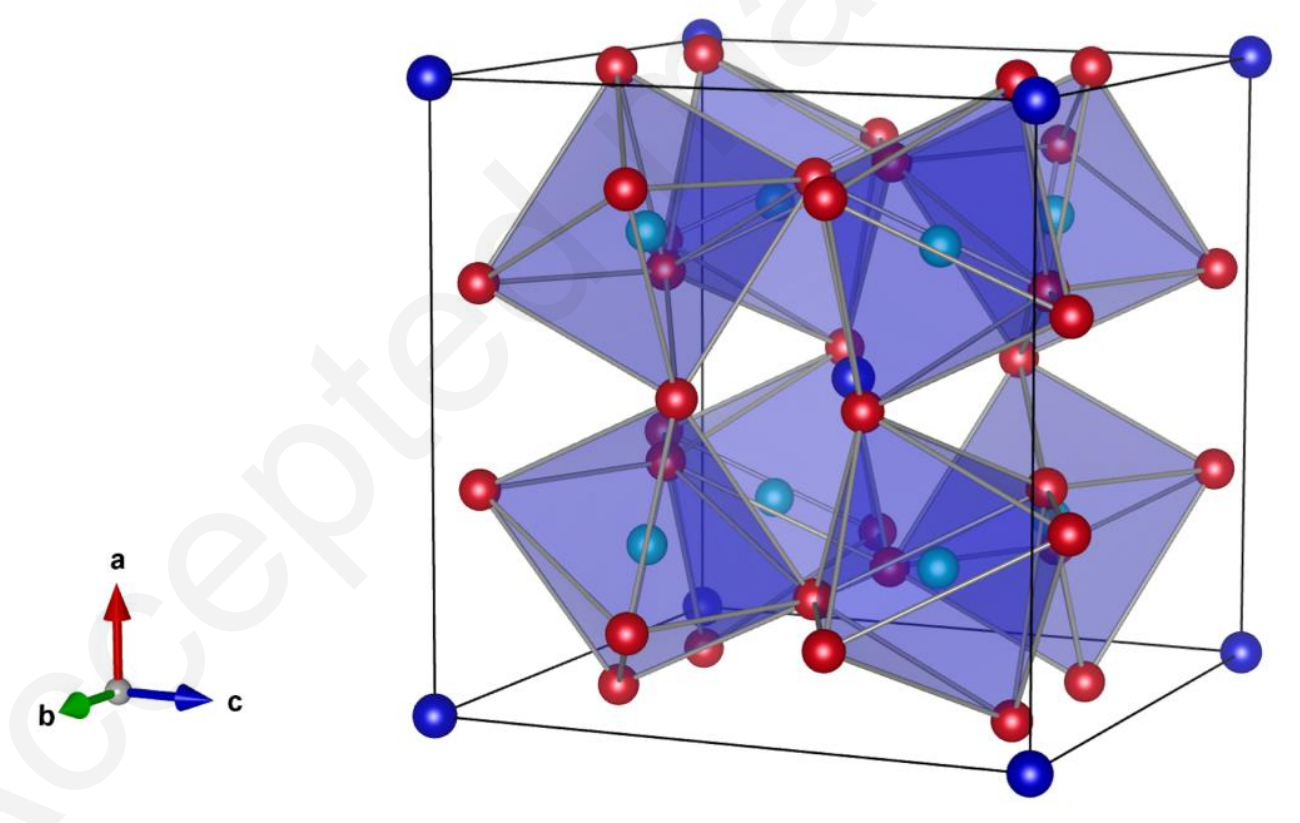

Fig. 7. Cubic crystal structure of filled skutterudites $\square M_{4} X_{12}$ described in the space group $\operatorname{Im} \overline{3}$. The atoms filling the voids are shown in dark blue while the $M$ and $X$ atoms are shown in light blue and red, respectively. The tilted octahedral coordination of the $M$ atoms is represented in blue. 
The elemental unit cell possesses 32 atoms ( $8 M$ atoms and $24 X$ atoms) arranged in eight $M X_{3}$ units. Out of the eight cubes into which the $X_{4}$ complexes are inserted, two of them remain empty. These two voids, also referred to as "cages" in the literature, are nevertheless sufficiently large to accommodate various foreign species. This interesting ability of the structure to host various elements in these cages is the key crystallographic characteristic of skutterudites, which shapes their thermal transport [29,30]. To highlight the presence of these two voids, the chemical formula is commonly written as $\square_{x} M_{4} X_{12}$ where $\square$ refers to a void and $0 \leq x \leq 1$.

Among the different binaries of this family, $\mathrm{CoSb}_{3}$ stands out as the most prominent compound that has been extensively investigated due to its excellent thermoelectric properties $[29,30,97,98]$. This binary, which behaves as a $p$-type semiconductor, can be driven towards a $n$-type compound by providing additional electrons either through partial substitutions on the $\mathrm{Co}$ or $\mathrm{Sb}$ sites or through insertion of a third elements into the empty voids of the crystalline lattice $[29,30,99,100]$. In $\mathrm{CoSb}_{3}$, these voids remain partially filled, with the solubility limit of the inserted element being strongly dependent on its nature. Alkali (Li, Na, K), alkaline-earth $(\mathrm{Mg}, \mathrm{Ca}, \mathrm{Sr}, \mathrm{Ba})$, rare-earth $(\mathrm{La}, \mathrm{Ce}, \mathrm{Yb}, \mathrm{Eu})$ as well as several transition metals or metalloids (Tl, Ga, In) have been successfully inserted into the voids of $\mathrm{CoSb}_{3}$, with $x$ typically varying between 0.1 and 0.5 [101-114]. In addition to these electropositive cations, electronegative fillers $(\mathrm{Br}, \mathrm{Cl}, \mathrm{S})$ have also been demonstrated to fill the cages [115-117].

The presence of these guest atoms has two important consequences on the transport properties of $\mathrm{CoSb}_{3}$. Firstly, the additional electrons provided by the inserted cations progressively drive the electronic properties from a semiconducting to a heavily-doped semiconducting behavior, leading to a significant increase in the power factor $\alpha^{2} / \rho$ due to the significant concomitant reduction in $\rho$ and increase in $\alpha[29,30]$. This last characteristic originates from the peculiar shape of the conduction bands [29,30,98], which can be advantageously manipulated depending on the nature of the inserted element $[29,30,118]$. Secondly, the inserted cations are loosely bounded to the cage framework, resulting in large 
thermal vibrations about their equilibrium position [29,30]. These vibrations, usually modelled as Einstein oscillators [29,30], are associated with optical, low-group-velocity phonon modes that strongly modify the phonon spectrum of $\mathrm{CoSb}_{3}$ at low energies [119]. These low-energy optical modes efficiently disrupt the heat-carrying acoustic phonons and hence, contribute to strongly lower the lattice thermal conductivity from $15 \mathrm{~W} \mathrm{~m}^{-1} \mathrm{~K}^{-1}$ in $\mathrm{CoSb}_{3}$ to around $1.5 \mathrm{~W} \mathrm{~m}^{-}$ ${ }^{1} \mathrm{~K}^{-1}$ at $300 \mathrm{~K}$ for various partially-filled compositions $[29,30]$. It is this remarkable trait that made skutterudites a fruitful area of research for designing novel, highly-efficient thermoelectric compounds. Combined with high power factors, this limited ability to transport heat leads to high $Z T$ values of 1.0 near $800 \mathrm{~K}$ [29,30,101-118]. Benefiting from either nanostructuration, multiple-filling approach or optimization of the filling fraction by specific metallurgical routes, further enhancement of these $Z T$ values up to 1.5 could be achieved $[118,120-122]$.

The presence of two voids per unit cell naturally raises the question whether fully-filled skutterudites exist. The positive answer to this intriguing question, combined with the ZintlKlemm concept, considerably widens the experimentally-accessible compositional landscape of skutterudites $[29,30,123,124]$. Filled skutterudites, the first of which $\mathrm{LaFe}_{4} \mathrm{P}_{12}$ was synthesized in 1977 [125], have a general chemical formula written as $R^{4+}\left[T_{4} X_{12}\right]^{4-}$ where $T$ are transition metals of group VIII (Fe, Ru and $\mathrm{Os})$ and $R$ is a tetravalent element $[29,30]$. The charge balance achieved between the filling element $R$ and the complexes $T_{4} X_{12}$ yields diamagnetic semiconductors in agreement with the Zintl-Klemm formalism. However, only very few elements satisfy the stringent requirement of being tetravalent, with most of the species inserted into the cages of the $T_{4} X_{12}$ structure being rather divalent or trivalent $[29,30]$. The deficit of electrons can be in fact compensated by substitutions on either the $T$ or $X$ sites such as, for instance, Co partially replacing Fe. Such an aliovalent substitution has been particularly studied in quaternary compositions of the type $R_{y} \mathrm{Fe}_{4-x} \mathrm{Co}_{x} \mathrm{Sb}_{12}$ with $R$ being mainly $\mathrm{Ce}$ or $\mathrm{Yb}[29,30,126]$. Increasing the Co content nevertheless impacts the concentration $y$ of the 
$R$ cations, which is then lower than its upper limit of 1 . Depending on the concentrations of $R$ and Co, both $n$ - and $p$-type electrical conduction can be achieved, with the latter being observed when the inequality $4-x-3 y>0$ is fulfilled. Although numerous $p$-type series with various filling elements have been investigated [29,30,118], the series $\mathrm{Ce}_{y} \mathrm{Fe}_{4-x} \mathrm{Co}_{x} \mathrm{Sb}_{12}$ remains the best $p$-type skutterudites known to date with peak $Z T$ values of 0.9 near $800 \mathrm{~K}$ that originate from heavilydoped semiconducting electrical properties combined with low lattice thermal conductivity values on the order of $1.5 \mathrm{~W} \mathrm{~m}^{-1} \mathrm{~K}^{-1}$ at $300 \mathrm{~K}$ [126]. Various strategies, similar to those adopted for $n$-type skutterudites, have been considered to further enhance these $Z T$ values, including inserting simultaneously several filler elements or inducing nano-scale precipitates by engineering the synthesis process $[29,30,118]$. However, none of these attempts have thus far successfully raised the $Z T$ values to those achieved in their $n$-type counterparts.

Due to these high thermoelectric performances, significant efforts are currently being devoted to integrate both $n$-type and $p$-type skutterudites into TEGs for terrestrial applications in power generation, with continuous progress being made to optimize notably the conversion efficiency [127-129]. On the space application side, $n$-type skutterudites remain the leading candidates for integration into RTGs and, after more than two decades of intense research endeavor, will likely integrate the 48-couple PbTe/TAGS RTGs currently powering the Mars

Curiosity rover. Recent performance evaluation of skutterudite-containing RTG have demonstrated that higher performances may be achieved with equivalent architecture and operational lifetime [130].

\subsection{Novel materials operating above $1000 \mathrm{~K}$}

While many families of thermoelectric materials exhibit their maximum thermoelectric performances below $800 \mathrm{~K}$, only few are known to be able to operate at temperatures up to $1300 \mathrm{~K}$ while, concomitantly, surpassing the thermoelectric properties of the traditionally- used 
$\mathrm{Si}_{1-x} \mathrm{Ge}_{x}$ alloys [47]. One of the most prominent examples of such compounds are provided by Zintl phases that constitute an important, wide class of materials, the bonding properties of which lie at the borders between ionic and covalent networks [131-133]. The complexity and diversity of their crystal structure, along with charge carrier mobilities that remains sufficiently high, are important ingredients to design novel efficient thermoelectric materials. The crystal structure of Zintl phases can harbor various sub-units such as 0 -dimensional ( $A_{14} M \mathrm{Sb}_{11}$ with $A$ $=\mathrm{Ca}, \mathrm{Yb}$ and $M=\mathrm{Mn}, \mathrm{Al}, \mathrm{Mg}), 1$-dimensional $\left(A_{5} M_{2} \mathrm{Sb}_{6}\right.$ with $A=\mathrm{Ca}, \mathrm{Sr}, \mathrm{Eu}, \mathrm{Yb}$ and $M=\mathrm{Al}$, Ga, In or $A_{3} M \mathrm{Sb}_{3}$ with $A=\mathrm{Ca}, \mathrm{Sr}, \mathrm{Ba}$ and $\left.M=\mathrm{Al}, \mathrm{Ga}, \mathrm{In}\right), 2$-dimensional $\left(A \mathrm{Zn}_{2} \mathrm{Sb}_{2}\right.$ with $A=$ $\mathrm{Ca}, \mathrm{Sr}, \mathrm{Eu}$ or $\mathrm{Yb}$ ) or 3-dimensional (clathrates for instance) [32-39,54,134-137].

So far, the $p$-type Zintl phase $\mathrm{Yb}_{14} \mathrm{MnSb}_{11}$ shows the best thermoelectric performances with a maximum $Z T$ value of 1.2 at $1273 \mathrm{~K}$ [54]. Such a value originates from the combination of semiconducting-like electronic properties, which can be adjusted by doping on the $\mathrm{Yb}$ site with $\mathrm{La}$ or $\mathrm{Lu}$ for instance or on the $\mathrm{Mn}$ site with $\mathrm{Zn}$ or $\mathrm{Al}$ [138-140], and very low lattice thermal conductivity that is mostly due to the complex crystal structure of this compound [141]. Due to its high thermoelectric performances and good thermal stability at high temperatures, this compound is currently being integrated in RTGs by NASA's JPL [142], and could thus replace $\mathrm{Si}_{1-x} \mathrm{Ge}_{x}$ alloys in future space missions.

Compared to $p$-type Zintl phases, only few $n$-type analogues have been investigated to date [143-145]. As the most promising $n$-type counterpart to $\mathrm{Yb}_{14} \mathrm{MnSb}_{11}, \mathrm{Mg}_{3} \mathrm{Sb}_{2}$ has recently emerged as one of the best $n$-type thermoelectric material known so far [146-153]. This discovery stirred up strong interest, giving rise to significant efforts within the thermoelectric community to explore in detail the chemistry and physics of this compound and of its solid solution with $\mathrm{Mg}_{3} \mathrm{Bi}_{2}$ [146-154]. As many other thermoelectric compounds, defect chemistry plays an important role. Counterbalancing the inherent $\mathrm{Mg}$ vacancies, due to the $\mathrm{Mg}$ 's high vapor pressure and reactivity, is necessary to achieve $n$-type electrical properties $[146,149,150]$. $n$-type samples have been successfully obtained by either using an excess amount of $\mathrm{Mg}$ in the 
nominal composition (that is, $\mathrm{Mg}_{3.2} \mathrm{Sb}_{2}$ ) or by annealing the samples under $\mathrm{Mg}$-rich conditions at high temperatures [146-153]. Although a full solid solution between semiconducting $\mathrm{Mg}_{3} \mathrm{Sb}_{2}$ and semi-metallic $\mathrm{Mg}_{3} \mathrm{Bi}_{2}$ exists, optimal thermoelectric properties are obtained for an equiatomic ratio, that is, for the composition $\mathrm{Mg}_{3.2} \mathrm{Sb}_{1.5} \mathrm{Bi}_{1.5}[149,151,152]$. The combination of semiconducting-like properties that originate from the high valley degeneracy of the conduction bands [154] and very low lattice thermal conductivity values that remain below $1 \mathrm{~W} \mathrm{~m}^{-1} \mathrm{~K}^{-1}$ above $300 \mathrm{~K}$ leads to peak $Z T$ values ranging between 1.5 and up to 1.8 at $800 \mathrm{~K}$ in optimized compositions [146-153]. Further investigations will be important to determine their thermal stability at high temperatures and whether their integration into thermoelectric generators is viable due to the possible high reactivity of $\mathrm{Mg}$. In addition, designing other highly-efficient $n$ type Zintl phases will be an interesting undertaking, paving the way to the development of allZintl thermoelectric generators with improved conversion efficiencies.

Mo-based cluster compounds form another broad family of compounds that are able to operate above $1000 \mathrm{~K}$ due to their very high melting points (typically between 1400 and 1800 K) [155-157]. The crystal structures of these compounds is formed by covalently-bounded Mo$X(X=\mathrm{S}, \mathrm{Se}$ or $\mathrm{Te})$ cluster units, the size and geometry of which can vary from $\mathrm{Mo}_{3}$ up to $\mathrm{Mo}_{3}$ (Fig. 8). The three-dimensional arrangement of these clusters leaves large empty voids or tunnels which can be filled by various cations (alkali, alkaline-earth or rare-earth). Both characteristics result in complex crystal structures with a large number of atoms per unit cell $N$ leading to a high number of optical phonon branches $(3 N-3)$ that largely outweighs the number of acoustic phonon branches (3). Because optical branches are mostly dispersionless, they contribute only weakly to the propagation of heat. Together with the presence of low-energy optical modes associated with the thermal motion of the cations, their large number helps to reduce the phase space available for acoustic phonons and hence, the sound velocities, ultimately concurring to significantly lower the lattice thermal conductivity down to $0.5 \mathrm{~W} \mathrm{~m}^{-}$ ${ }^{1} \mathrm{~K}^{-1}$ above $300 \mathrm{~K}$ [158-169]. 


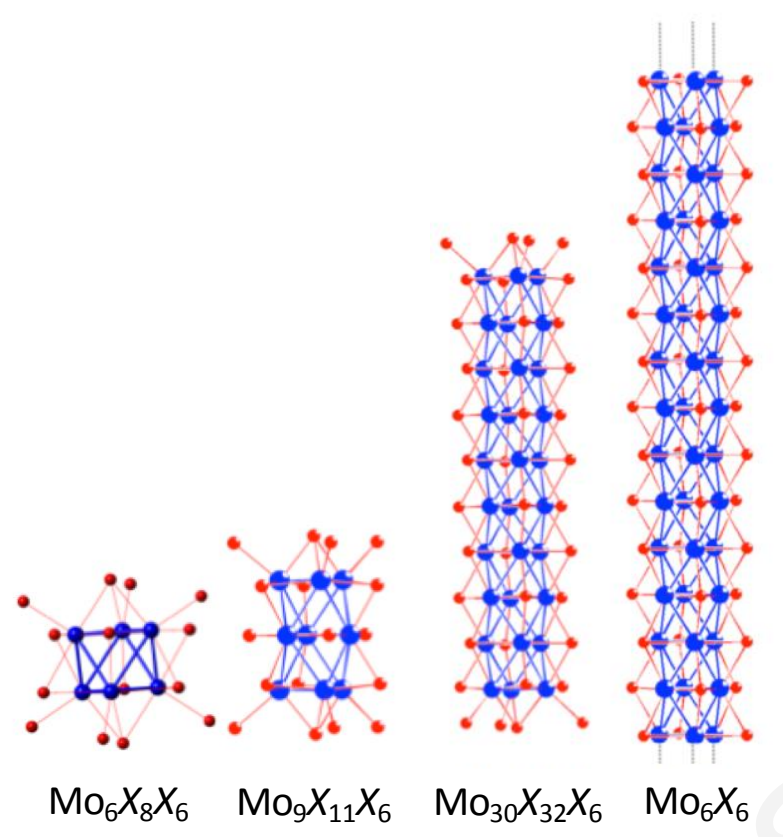

Fig. 8. Examples of Mo- $X$ clusters $(X=\mathrm{S}$, Se or Te) of various sizes. Several basic units $\mathrm{Mo}_{6} X_{8} X_{6}$ can be condensed to form longer chain-like clusters that are then arranged to form a three-dimensional framework. In the limit of infinite length, compounds $\operatorname{Mo}_{6} X_{6}$ are obtained.

The electronic properties of these compounds can be rationalized by considering the socalled metallic electron count (MEC) that corresponds to the number of available electrons for metal-metal bonding. For each types of clusters, an optimal MEC can be predicted either from simple electron counting rules or by electronic band structure calculations [154]. When this optimal count is achieved, a semiconducting ground state is predicted to occur, which is more favorable from a thermoelectric point of view. However, in most of the cases studied experimentally so far, the total MEC remains below its optimum value, explaining the metallic properties observed in many compounds [158-169]. This drawback can be partially overcome in some compounds either by tuning the concentration of the cations or by inserting additional cations. These two strategies are exemplified by the $p$-type $\mathrm{Ag}_{x} \mathrm{Mog}_{9} \mathrm{Se}_{11}$ and $\mathrm{Ag}_{3} M_{2} \mathrm{Mo}_{15} X_{19}(M$ $=\mathrm{K}, \mathrm{In}, \mathrm{Tl} ; X=\mathrm{S}$ or Se) compounds [158-169]. In the former system, increasing $x$ from $x=3.4$ up to $x=3.9$ drives the transport properties from metallic-like to heavily-doped 
semiconducting-like, accompanied by a significant increase in the $Z T$ values that reach 0.65 at $800 \mathrm{~K}$ [169]. This high value, equivalent to that achieved in the $\mathrm{Si}_{1-x} \mathrm{Ge}_{x}$ alloys, also originates from the very low lattice thermal conductivity $\left(0.4 \mathrm{~W} \mathrm{~m}^{-1} \mathrm{~K}^{-1}\right.$ at $\left.800 \mathrm{~K}\right)$ that approaches its minimum value, comparable to that achieved in amorphous solids. In the family $\mathrm{Ag}_{3} M_{2} \mathrm{Mo}_{15} X_{19}$, all the ternaries $M_{2} \mathrm{Mo}_{15} X_{19}$ are metallic with interesting low-temperature physical properties that include the coexistence of superconductivity and a charge density wave, depending on the nature of the $M$ cations $[170,171]$. The thermoelectric performances can be then improved by inserting $\mathrm{Ag}$, which helps to increase the MEC closer to its optimum value $[158,163,166]$. Despite the resulting improvement of the power factor, a semiconducting state is not achieved. The $Z T$ values are nevertheless enhanced with a maximum $Z T$ value of 0.45 at $1100 \mathrm{~K}$ obtained in the $M=$ In compound [158]. Without any exceptions, all the compounds investigated so far possess $p$-type electronic properties. Thus, whether $n$-type Mo-based cluster compounds exist remains an open question. Should the answer be positive or negative, further studies on the $p$ type compounds will be an interesting undertaking to determine whether they can compete or even surpass the performances of the record-holder $\mathrm{Yb}_{14} \mathrm{MnSb}_{11}$.

\subsection{Beyond thermoelectric properties}

Although optimized thermoelectric properties are a key aspect the thermoelectric materials should possess, they should nevertheless meet several other important requirements for integration into RTGs and space qualification. In this respect, their long-term chemical stability at the operating hot side temperature, their thermomechanical properties and their ability to be radiation-tolerant are also critical aspects that explain the time necessary to deliver space qualification [127-130]. Nearly all the above-mentioned thermoelectric materials are mainly composed of pnictogen elements ( $\mathrm{Sb}, \mathrm{Te}$ or $\mathrm{Se}$ ), the high vapor pressure of which often results in volatilization at high temperatures. To avoid this deleterious effect and increase the 
stability of the thermoelectric materials at the targeted operating temperature, protective coatings must cover the thermoelectric legs. In addition, interdiffusion of elements usually occurs at the joints of the TEGs [127-129,172,173]. The diffusion of elements into the thermoelectric materials can act as dopants, potentially degrading the thermoelectric performances. To circumvent this important issue, diffusion barriers are usually inserted between the thermoelectric materials and the electrical contacts in order to block the migration of the chemical species.

The high temperature gradient the thermoelectric materials are subjected to can potentially lead to high thermomechanical stresses that originate from the thermal expansion coefficient of the thermoelectric materials that can significantly differ from those of the metallic contacts. Although the mechanical properties of most of the thermoelectric materials described in the preceding sections remain poorly investigated so far, they typically behave as ceramics and are thus often fragile. The high stress levels that can develop within each legs can result in their breakage, thereby strongly limiting the lifetime of the module. The stress levels can be nevertheless mitigated by adapting the surface area and the length (typically $1 \mathrm{~cm}$ ) of the $n$-and p-type legs.

While all these aspects are common to TEGs developed for terrestrial applications in power generation at high temperatures, the tolerance of the thermoelectric materials to radiations is a specific, yet critical, facet of space applications $[9,174,175]$. In RTGs, the thermoelectric materials are subject to bombardment by particles and electromagnetic radiations emanating from the internal radioisotope fuel source and from the outer space. While the dose received from external sources is strongly mission dependent, the internal bombardment can be estimated. The nuclear decay of the radioisotope fuel can produce alpha, gamma ray and fast neutron emissions, all of which being susceptible to provoke random defects in the active thermoelectric materials. Because their transport properties are highly sensitive to the amount of induced charged defects (vacancies and interstitials) that alter the 
carrier concentration, determining the evolution of the thermoelectric properties under spacelike irradiation conditions is an important test. Moreover, gamma rays can activate various nuclides, both short-lived and long-lived, the decay of which can induce $n$ - or $p$-type doping, potentially also contributing to shift the carrier concentrations away from their optimized values. While all the thermoelectric materials launched in space have, de facto, proved their tolerance to radiations, many other candidates remain to be investigated in future studies. As a relevant example, $\mathrm{Bi}_{2} \mathrm{Te}_{3}$-based alloys have been recently shown to be also radiation-tolerant to a level sufficient to envisage 10 -year-long missions [174,175]. By subjecting $\mathrm{Bi}_{2} \mathrm{Te}_{3}$-based modules to neutron irradiation with a fluence equivalent to that integrated over the entire targeted lifetime of the mission, the thermoelectric performances were found to be minimally impacted, demonstrating the high radiation hardness of these materials. This aspect further highlights the need to achieve optimum thermoelectric performances over an extended carrier concentration range, which can be beneficial for minimizing the detrimental effect of radiations on the electronic properties.

\section{Conclusions}

In this brief review, we have surveyed several families of materials that exhibit transport properties relevant for thermoelectric applications in power generation, making them prime candidates for being integrated in the next generation of RTGs. A central aspect of these materials is their high $Z T$ values that can be optimized through proper doping strategies. They combine two basic requirements, that is, semiconducting-like electronic properties with low lattice thermal conductivity values. The wide interest in these materials is testified by the significant, ever-growing amount of literature data available for these families. While significant advances have been achieved on the material side, several issues regarding their integration in RTGs remain to be solved, notably regarding their thermal stability over long 
periods of time. Further investigations on these materials and on other related families might uncover novel, highly-efficient thermoelectric materials that will enable further enhancing the output performances of RTGs. The successful integration of these materials into RTGs may be also beneficial for the development of TEGs and their more widespread use in terrestrial applications, thereby contributing to mitigate mankind's fingerprint on the global climate.

\section{Acknowledgements}

The authors thank the European Space Agency (ESA/ESTEC) under the ESA/ESTEC Contracts C20179 and NPI Contracts No. 22955/09/NL/PA and 40001134346/15/NL/RA for financial support. 


\section{References}

1. Rowe, D. M. in Thermoelectrics and its Energy Harvesting: Modules, Systems, and Applications in Thermoelectrics, ed. D. M. Rowe, CRC Press, Boca Raton, 2012.

2. Snyder, G. J., Toberer, E. S. Complex thermoelectric materials. Nature Mater. 7, 105-114 (2008).

3. Bell, L. E. Cooling, Heating, Generating Power, and Recovering Waste Heat with Thermoelectric Systems. Science 321, 1457-1461 (2008).

4. Bauer, S. Flexible Electronics. Nature Mater. 12, 871-872 (2013).

5. Xu, Q., Qu, S., Ming, C., Qiu, P., Yao, Q., Zhu, C., Wei, T.-R., He, J., Shi, X., Chen, L. Conformal organic-inorganic semiconductor composites for flexible thermoelectrics. Energy Environ. Sci. 13, 511-518 (2020).

6. Qi, Y., McAlpine, M. C. Nanotechnology-enabled flexible and biocompatible energy harvesting. Energy Environ. Sci. 3, 1275-1285 (2010).

7. Wan, C., Gu, X., Dang, F., Itoh, T., Wang, Y., Sasaki, H., Kondo, M., Koga, K., Yabuki, K., Snyder, G. J., Yang, R., Koumoto, K. Flexible n-type thermoelectric materials by organic intercalation of layered transition metal dichalcogenide $\mathrm{TiS}_{2}$. Nat. Mater. 14, 622-627 (2015).

8. El Oualid, S., Kosior, F., Dauscher, A., Candolfi, C., Span, G., Mehmedovic, E., Paris, J., Lenoir, B. Innovative design of bismuth-telluride-based thermoelectric micro-generators with high output power. Energy Environ. Sci. 13, 3579-3591 (2020).

9. Ambrosi, R. M., Williams, H., Watkinson, E. J., Barco, A., Mesalam, R., Crawford, T., Bicknell, C., Samara-Ratna, P., Vernon, D., Bannister, N., Ross, D., Sykes, J., Perkinson, M.C., Brugess, C., Stroud, C., Gibson, S., Godfrey, A., Slater, R. G., Reece, M. J., Chen, K., Simson, K., Tuley, R., Sarsfield, M., Tinsley, T. P., Stephenson, K., Freis, D., Vigier, J.-F., Konings, R. J. M., Fongarland, C., Libessart, M., Merrifield, J., Kramer, D. P., Byrne, J., 
Foxcroft, B. European Radioisotope Thermoelectric Generators (RTGs) and Radioisotope Heater Units (RHUs) for Space Science and Exploration. Space Sci. Rev. 215(55) (2019).

10. Scherrer, S., Vikhor, L., Lenoir, B., Dauscher, A., Poinas, P. Solar thermoelectric generators based on skutterudites, J. Power Sources 115, 141-148 (2003).

11. Lenoir, B., Dauscher, A., Poinas, P., Scherrer, S., Vikhor, L. Electrical performance of skutterudites solar thermoelectric generators, Appl. Therm. Eng. 23, 1407-1415 (2003).

12. Jaziri, N., Boughamoura, A., Müller, J., Mezghani, B., Tounsi, F., Ismail, M. A comprehensive review of Thermoelectric Generators: Technologies and common applications. Energy Rep. https://doi.org/10.1016/j.egyr.2019.12.011 (2019).

13. Hammel, T., Bennett, R., Otting, W., Fanale, S., Multi-Mission Radioisotope Thermoelectric Generator (MMRTG) and performance prediction model. 7th International Energy Conversion Engineering Conference, Denver, Colorado (2009).

14. Yu, J., Xing, Y., Hu, C., Huang, Z., Qiu, Q., Wang, C., Xia, K., Wang, Z., Bai, S., Zhao, X., Chen, L., Zhu, T. Half-Heusler Thermoelectric Module with High Conversion Efficiency and High Power Density. Adv. Energy Mater. 10, 2000888 (2020).

15. Muto, A., Yiang, J., Poudel, B., Ren, Z., Chen, G. Skutterudite Unicouple Characterization for Energy Harvesting Applications. Adv. Energy Mater. 3, 245-251 (2013).

16. Hong, M., Zheng, K., Lyv, W., Li, M., Qu, X., Sun, Q., Xu, S., Zou, J., Chen, Z.-G. Computer-aided design of high-efficiency GeTe-based thermoelectric devices. Energy Environ. Sci. 13, 1856-1864 (2020).

17. Zhu, T., Liu, Y., Fu, C., Heremans, J. P., Snyder, G. J., Zhao, X. Compromise and Synergy in High-Efficiency Thermoelectric Materials. Adv. Mater. 29, 1605884 (2017).

18. Pei, Y., LaLonde, A., Wang, H., Chen, L., Snyder, G. J. Convergence of Electronic Bands for High Performance Bulk Thermoelectrics. Nature 473, 66-69 (2011). 
19. Zhang, J., Liu, R., Cheng, N., Zhang, Y., Yang, J., Uher, C., Shi, X., Chen, L., Zhang, W. High-Performance Pseudocubic Thermoelectric Materials from Non-cubic Chalcopyrite Compounds. Adv. Mater. 26, 3848-3853 (2014).

20. Heremans, J. P., Jovovic, V., Toberer, E. S., Saramat, A., Kurosaki, K., Charoenphakdee, A., Yamanaka, S., Snyder, G. J. Enhancement of thermoelectric efficiency in PbTe by distortion of the electronic density of states. Science 321, 554-557 (2008).

21. Heremans, J. P., Wiendlocha, B., Chamoire, A. M. Resonant levels in bulk thermoelectric semiconductors. Energy Environ. Sci. 5, 5510-5530 (2012).

22. Jaworski, C. M., Kulbachinskii, V., Heremans, J. P. Resonant level formed by tin in $\mathrm{Bi}_{2} \mathrm{Te}_{3}$ and the enhancement of room-temperature thermoelectric power. Phys. Rev. B 80, 233201 (2009).

23. Wiendlocha, B., Vaney, J.-B., Candolfi, C., Dauscher, A., Lenoir, B., Tobola, J. An Sninduced resonant level in $\beta-\mathrm{As}_{2} \mathrm{Te}_{3}$. Phys. Chem. Chem. Phys. 20, 12948-12957 (2018).

24. Misra, S., Wiendlocha, B., Tobola, J., Fesquet, F., Dauscher, A., Lenoir, B., Candolfi, C. Band structure engineering in $\mathrm{Sn}_{1.03}$ Te through an In-induced resonant level. J. Mater. Chem. C 8, 977-988 (2020).

25. Kaidanov, V. I., Ravich, Y. I. Deep and resonance states in $\mathrm{A}^{\mathrm{IV}} \mathrm{B}^{\mathrm{VI}}$ semiconductors. Sov. Phys. Usp. 28, 31 (1985).

26. Wiendlocha, B. Thermopower of thermoelectric materials with resonant levels: PbTe:Tl versus PbTe:Na and $\mathrm{Cu}_{1-x} \mathrm{Ni}_{x}$. Phys. Rev. B 97, 205203 (2018).

27. Wang, H., LaLonde, A., Pei, Y., Snyder, G. J. The Criteria for Benefi cial Disorder in Thermoelectric Solid Solutions. Adv. Funct. Mater. 23, 1586-1596 (2013).

28. Sales, B. C., Mandrus, D., Williams, R. K. Filled Skutterudite Antimonides: A New Class of Thermoelectric Materials. Science 272, 1325-1328 (1996).

29. Rogl, G., Rogl, P. Skutterudites, a most promising group of thermoelectric materials. Curr. Opin. Green Sustain. Chem. 4, 50-57 (2017). 
30. Uher, C. in Thermoelectrics and its Energy Harvesting, edited by D. M. Rowe (CRC, 2012), Chap. 10.

31. Leszczynski, J., Da Ros, V., Lenoir, B., Dauscher, A., Candolfi, C., Masschelein, P., Hejtmanek, J., Kutorasinski, K., Tobola, J., Smith, R. I., Stiewe, C., Müller, E. Electronic band structure, magnetic, transport and thermodynamic properties of In-filled skutterudites $\mathrm{In}_{x} \mathrm{Co}_{4} \mathrm{Sb}_{12}$. J. Phys. D: Appl. Phys. 46, 495106 (2013).

32. Nolas, G. S. in The Physics and Chemistryof Inorganic Clathrates, ed. G. S. Nolas, Springer (2014).

33. Dolyniuk, J.-A., Owens-Baird, B., Wang, J., Zaikina, J. V., Kovnir, K. Clathrate thermoelectrics. Mater. Sci. Eng. R. 108, 1-46 (2016).

34. Christensen, M., Johnsen, S., Iversen, B. B. Thermoelectric clathrates of type I. Dalton Trans. 39, 978-992 (2010).

35. Nolas, G. S., Cohn, J. L., Slack, G. A., Schujman, S. B. Semiconducting Ge clathrates: Promising candidates for thermoelectric applications. Appl. Phys. Lett. 73, 178 (1998).

36. Suekuni, K., Avila, M. A., Umeo, K., Takabatake, T. Cage-size control of guest vibration and thermal conductivity in $\mathrm{Sr}_{8} \mathrm{Ga}_{16} \mathrm{Si}_{30-x} \mathrm{Ge}_{x}$. Phys. Rev. B 75, 195210 (2007).

37. Lory, P.-F., Pailhès, S., Giordano, V. M., Euchner, H., Nguyen, N. D., Ramlau, R., Borrmann, H., Schmidt, M., Baitinger, M., Ikeda, M., Tomes, P., Mihalkovic, M., Allio, C., Johnson, M. R., Schober, H., Sidis, Y., Bourdarot, F., Regnault, L. P., Ollivier, J., Paschen, S., Grin, Yu., de Boissieu, M. Direct measurement of individual phonon lifetimes in the clathrate compound Ba7.81Ge40.67Au5.33. Nat. Commun. 8, 491 (2017).

38. Aydemir, U., Candolfi, C., Borrmann, H., Baitinger, M., Ormeci, A., Carrillo-Cabrera, W., Chubilleau, C., Lenoir, B., Dauscher, A., Oeschler, N., Steglich, F., Yu. Grin. Crystal structure and transport properties of $\mathrm{Ba}_{8} \mathrm{Ge}_{43}{ }_{3}$. Dalton Trans. 39, 1078-1088 (2010).

39. Baitinger, M., Böhme, B., Ormeci, A., Grin, Yu. "Solid state chemistry of clathrate phases: Crystal structure, chemical bonding and preparation routes," in The Physics and Chemistry of 
Inorganic Clathrates (Springer, 2014), pp. 35-64.

40. Tan, G., Zhao, L.-D., Kanatzidis, M. G. Rationally Designing High-Performance Bulk Thermoelectric Materials. Chem. Rev. 116, 12123-12149 (2016).

41. Chen, G., Li, Y., Bick, M., Chen, J. Smart Textiles for Electricity Generation. Chem. Rev. (2019) https:/dx.doi.org/10.1021/acs.chemrev.9b00821.

42. Shi, X.-L., Zou, J., Chen, Z.-G. Advanced Thermoelectric Design: From Materials and Structures to Devices. Chem. Rev. (2020). https://dx.doi.org/10.1021/acs.chemrev.0c00026.

43. Yu, Y., Cagnoni, M., Cojocaru-Mirédin, O., Wuttig, M. Chalcogenide Thermoelectrics Empowered by an Unconventional Bonding Mechanism. Adv. Funct. Mater. 30, 1904862 (2020).

44. Wuttig, M., Deringer, V. L., Gonze, X., Bichara, C., Raty, J.-Y. Incipient metals: Functiona 1 materials with a unique bonding mechanism. Adv. Mater. 30, 1803777 (2018).

45. Witting, I. T. Chasapis, T. C., Ricci, F., Peters, M., Heinz, N. A., Hautier, G., Snyder, G. J. The Thermoelectric Properties of Bismuth Telluride. Adv. Electron. Mater. 5, 1800904 (2019). 46. Pei, Y., Wang, H., Snyder, G. J. Band Engineering of Thermoelectric Materials. Adv. Mater. 24, 6125-6135 (2012).

47. Fleurial, J.-P., Vandersande, J. Progress in the optimization of $n$-type and $p$-type SiGe thermoelectric materials. AIP Conf. Proc. 271, 759-764 (1993).

48. Li, C. W., Hellman, O., Ma, J., May, A. F., Cao, H. B., Chen, X., Christianson, A. D., Ehlers, G., Singh, D. J., Sales, B. C., Delaire, O. Phonon Self-Energy and Origin of Anomalous Neutron Scattering Spectra in SnTe and PbTe Thermoelectrics. Phys. Rev. Lett. 112, 175501 (2014).

49. Delaire, O., Ma, J., Marty, K., May, A. F., McGuire, M. A., Du, M.-H., Singh, D. J., Podlesnyak, A., Ehlers, G., Lumsden, M. D., Sales, B. C. Giant anharmonic phonon scattering in PbTe. Nat. Mater. 10, 614-619 (2011).

50. Lenoir, B., Scherrer, H., Caillat, T. An Overview of Recent Developments of BiSb Alloys in Semiconductors and Semimetals, vol. 69, Ed. T. M. Tritt, Academic Press (2001), Chap. 4, 
p. $101-137$.

51. Kim, S. W., Cho, M. K., Mishima, Y., Choi, D. C. High temperature thermoelectric properties of $p$ - and $n$-type $\beta$-FeSi2 with some dopants. Intermetallics 11, 399-405 (2003).

52. Nishida, I. Study of Semiconductor-to-Metal Transition in Mn-Doped FeSi2. Phys. Rev. B 7, 2710-2713 (1973).

53. Biswas, K., He, J., Blum, I. D., Wu, C.-I., Hogan, T. P., Seidman, D. N., Dravid, V. P., Kanatzidis, M. G. High-performance bulk thermoelectrics with all-scale hierarchical architectures. Nature 489, 414-418 (2012).

54. Brown, S. R., Kauzlarich, S. M., Gascoin, F., Snyder, G. J. Yb ${ }_{14} \mathrm{MnSb}_{11}$ : New High Efficiency Thermoelectric Material for Power Generation. Chem. Mater. 18, 1873-1877 (2006). 55. May, A. F., Fleurial, J.-P., Snyder, G. J. Thermoelectric performance of lanthanum telluride produced via mechanical alloying. Phys. Rev. B 78, 125205 (2008).

56. Yu, J., Xing, Y., Hu, C., Huang, Z., Qiu, Q., Wang, C., Xia, K., Wang, Z., Bai, S., Zhao, X., Chen, L., Zhu, T. Half-Heusler Thermoelectric Module with High Conversion Efficiency and High Power Density. Adv. Energy Mater. 10, 2000888 (2020).

57. Zhao, L.-D., Lo, S.-H., Zhang, Y., Sun, H., Tan, G., Uher, C., Wolverton, C., Dravid, V. P., Kanatzidis, M. G. Ultralow thermal conductivity and high thermoelectric figure of merit in SnSe crystals. Nature 508, 373-378 (2014).

58. Chang, C., Wu, M., He, D., Pei, Y., Wu, C.-F., Wu, X., Yu, H., Zhu, F., Wang, K., Chen, Y., Huang, L., Li, J.-F., He, J., Zhao, L.-D. 3D charge and 2D phonon transports leading to high out-of-plane $Z T$ in $n$-type SnSe crystals. Science 360, 778-783 (2018).

59. Zaitsev, V. K., Fedorov, M. I., Gurieva, E. A., Eremin, I. S., Konstantinov, P. P., Samunin, A. Yu., Vedernikov, M. V. Highly effective $\mathrm{Mg}_{2} \mathrm{Si}_{1-x} \mathrm{Sn}_{x}$ thermoelectrics. Phys. Rev. B 74, 045207 (2006).

60. Zeier, W. G., Schmitt, J., Hautier, G., Aydemir, U., Gibbs, Z. M., Felser, C., Snyder, G. J. Engineering half-Heusler thermoelectric materials using Zintl chemistry. Nat. Rev. Mater. 1, 
$16032(2016)$.

61. Chung, D.-Y., Hogan, T., Brazis, P., Rocci-Lane, M., Kannewurf, C., Bastea, M., Uher, C., Kanatzidis, M. G. CsBi4Te6: A High-Performance Thermoelectric Material for LowTemperature Applications. Science 287, 1024-1027 (2000).

62. Zhang, B., Sun, J., Katz, H. E., Fang, F., Opila, R. L. Promising Thermoelectric Properties of Commercial PEDOT:PSS Materials and Their $\mathrm{Bi}_{2} \mathrm{Te}_{3}$ Powder Composites. ACS Appl. Mater. Interfaces 2, 3170-3178 (2010).

63. Zou, T. Xie, W., Feng, J., Qin, X., Weidenkaff, A. Recent Developments in $\beta-\mathrm{Zn}_{4} \mathrm{Sb}_{3}$ Based Thermoelectric Compounds. J. Nanomater. 642909 (2015).

64. Zhao, L.-D., He, J., Berardan, D., Lin, Y., Li, J.-F., Nan, C.-W., Dragoe, N. BiCuSeO oxyselenides: new promising thermoelectric materials. Energy Environ. Sci. 7, 2900-2924 (2014).

65. Fujita, K., Mochida, T., Nakamura, K. Jpn. J. Appl. Phys. 40, 4644-4647 (2001).

66. Candolfi, C., Ibrahim, D., Vaney, J.-B., Sassi, S., Masschelein, P., Dauscher, A., Lenoir, B. SnSe : Breakthrough or not Breakthrough? in Novel Thermoelectric Materials and Device Design, Eds. Skipidarov, S., Nikitin, M., p. 23-46, Springer Nature (2019).

67. Ibrahim, D., Vaney, J.-B., Sassi, S., Candolfi, C., Ohorodniichuk, V., Levinsky, P., Semprimoschnig, C., Dauscher, A., Lenoir, B. Reinvestigation of the thermal properties of single-crystalline SnSe. Appl. Phys. Lett. 110, 032103 (2017).

68. Sassi, S., Candolfi, C., Vaney, J.-B., Ohorodniichuk, V., Masschelein, P., Dauscher, A., Lenoir, B. Assessment of the thermoelectric performance of polycrystalline $p$-type SnSe. Appl. Phys. Lett. 104, 212105 (2014).

69. Chen, C.-L., Wang, H., Chen, Y.-Y., Day, T., Snyder, G. J. Thermoelectric properties of $p$ type polycrystalline SnSe doped with Ag. J. Mater. Chem. A 2, 11171-11176 (2014).

70. Brebrick, R. F., Strauss, A. J. Anomalous Thermoelectric Power as Evidence for TwoValence Bands in SnTe. Phys. Rev. 131, 104-110 (1963). 
71. Brebrick, R. F. Deviations from stoichiometry and electrical properties in SnTe. J. Phys. Chem. Solids 24, 27 (1963).

72. Tan, G., Zhao, L.-D., Shi, F., Doak, J. W., Lo, S.-H., Sun, H., Wang, P., Wolverton, C., Dravid, V. P., Uher, C., Kanatzidis, M. G. High Thermoelectric Performance of $p$-Type SnTe via a Synergistic Band Engineering and Nanostructuring Approach. J. Am. Chem. Soc. 136, 7006 (2014).

73. Tan, G., Shi, F., Doak, J. W., Sun, H., Zhao, L.-D., Wang, P., Uher, C., Wolverton, C., Dravid, V. P., Kanatzidis, M. G. Extraordinary role of $\mathrm{Hg}$ in enhancing the thermoelectric performance of $p$-type SnTe. Energy Environ. Sci. 8, 267 (2015).

74. Banik, A., Shenoy, U. S., Anand, S., Waghmare, U. W., Biswas, K. Mg Alloying in SnTe Facilitates Valence Band Convergence and Optimizes Thermoelectric Properties. Chem. Mater. 27, $581(2015)$.

75. Al Rahal Al Orabi, R., Hwang, J., Lin, C.-C., Gautier, R., Fontaine, B., Kim, W., Rhyee, J.S., Wee, D., Fornari, M. Ultralow Lattice Thermal Conductivity and Enhanced Thermoelectric Performance in SnTe:Ga Materials. Chem. Mater. 29, 612 (2017).

76. Littlewood, P. B., Mihaila, B., Schulze, R. K., Safarik, D. J., Gubernatis, J. E., Bostwick, A., Rotenberg, E., Opeil, C. P., Durakiewicz, T., Smith, J. L., Lashley, J. C. Phys. Rev. Lett. 105, 086404 (2010).

77. Ibrahim, D., Candolfi, C., Migot, S., Ghanbaja, J., Dauscher, A., Le Caër, G., Malaman, B., Semprimoschnig, C., Lenoir, B. Comprehensive study of the low-temperature transport properties of polycrystalline $\operatorname{Sn}_{1+x} \mathrm{Te}(x=0$ and 0.03$)$. Phys. Rev. Mater. 3, 085404 (2019).

78. Ibrahim, D., Ohorodniichuk, V., Candolfi, C., Semprimoschnig, C., Dauscher, A., Lenoir, B. Improved Thermoelectric Properties in Melt-Spun SnTe. ACS Omega 2, 7106 (2017).

79. Ibrahim, D., Misra, S., Migot, S., Ghanbaja, J., Dauscher, A., Malaman, B., Semprimoschnig, C., Candolfi, C., Lenoir, B. Transport properties of polycrystalline SnTe prepared by saturation annealing. RSC Adv. 10, 5996-6005 (2020). 
80. Wei, T.-R., Tan, G., Zhang, X., Wu, C.-F., Li, J.-F., Dravid, V. P., Snyder, G. J., Kanatzidis,

M. G. Distinct Impact of Alkali-Ion Doping on Electrical Transport Properties of Thermoelectric $p$-Type Polycrystalline SnSe. J. Am. Chem. Soc. 138, 8875-8882 (2016).

81. Zhang, L., Wang, J., Sun, Q., Qin, P., Cheng, Z., Ge, Z., Li, Z., Dou, S. Three-Stage InterOrthorhombic Evolution and High Thermoelectric Performance in Ag-Doped Nanolaminar SnSe Polycrystals. Adv. Energy Mater. 7, 1700573 (2017).

82. Chang, C., Tan, Q., Pei, Y., Xiao, Y., Zhang, X., Chen, Y.-X., Zheng, L., Gong, S., Li, J.F., He, J., Zhao, L.-D. Raising thermoelectric performance of $n$-type $\mathrm{SnSe}$ via $\mathrm{Br}$ doping and Pb alloying. RSC Adv. 6, 98216 (2016).

83. Pletikosić, I., von Rohr, F., Pervan, P., Das, P. K., Vobornik, I., Cava, R. J., Valla, T. Band Structure of the IV-VI Black Phosphorus Analog and Thermoelectric SnSe. Phys. Rev. Lett. 120, 156403 (2018).

84. Wang, Z., Fan, C., Shen, Z., Hua, C., Hu, Y., Sheng, F., Lu, Y., Fang, H., Qiu, Z., Lu, J., Liu, Z., Liu, W., Huang, Y., Xu, Z.-A., Shen, D. W., Zheng, Y. Defects controlled hole doping and multivalley transport in SnSe single crystals. Nat. Commun. 9, 47 (2018).

85. Kutorasinski, K., Wiendlocha, B., Kaprzyk, S., Tobola, J. Electronic structure and thermoelectric properties of $n$ - and $p$-type SnSe from first-principles calculations. Phys. Rev. B 91, 205201 (2015).

86. Li, C. W., Hong, J., May, A. F., Bansal, D., Chi, S., Hong, T., Ehlers, G., Delaire, O. Orbitally driven giant phonon anharmonicity in SnSe. Nat. Phys. 11, 1063 (2015).

87. Bansal, D., Hong, J., Li, C. W., May, A. F., Porter, W., Hu, M. Y., Abernathy, D. L., Delaire, O. Phonon anharmonicity and negative thermal expansion in SnSe. Phys. Rev. B 94, 054307 (2016).

88. Rabii, S. Energy-Band Structure and Electronic Properties of SnTe. Phys. Rev. 182, 821828 (1969).

89. Allgaier, R. S., Houston, B. Weak-Field Magnetoresistance and the Valence-Band Structure 
of SnTe. Phys. Rev. B 5, 2186-2197 (1972).

90. Moshwan, R., Yang, L., Zou, J., Chen, Z.-G. Eco-Friendly SnTe Thermoelectric Materials: Progress and Future Challenges. Adv. Funct. Mater. 27, 1703278 (2017).

91. Li, W., Wu, Y., Lin, S., Chen, Z., Li, J., Zhang, X., Zheng, L., Pei, Y. Advances in Environment-Friendly SnTe Thermoelectrics. ACS Energy Lett. 2, 2349-2355 (2017).

92. Zhang, Q., Liao, B., Lan, Y., Lukas, K., Liu, W., Esfarjani, K., Opeil, C., Broido, D., Chen, G., Ren, Z. High thermoelectric performance by resonant dopant indium in nanostructured SnTe. Proc. Nat. Acad. Sci. USA 110, 13261-13266 (2013).

93. Li, W., Zheng, L., Ge, B., Lin, S., Zhang, X., Chen, Z., Chang, Y., Pei, Y. Promoting SnTe as an Eco-Friendly Solution for p-PbTe Thermoelectric via Band Convergence and Interstitial Defects. Adv. Mater. 29, 1605887 (2017).

94. Bauer, E. D., Frederick, N. A., Ho, P.-C., Zapf, V. S., Maple, M. B. Superconductivity and heavy fermion behavior in $\mathrm{PrOs}_{4} \mathrm{Sb}_{12}$. Phys. Rev. B 65, 100506(R) (2002).

95. Ho, P.-C., Yanagisawa, T., Yuhasz, W. M., Dooraghi, A. A., Robinson, C. C., Butch, N. P., Baumbach, R. E., Maple, M. B. Superconductivity, magnetic order, and quadrupolar order in the filled skutterudite system $\operatorname{Pr}_{1-x} \mathrm{Nd}_{x} \mathrm{O}_{54} \mathrm{Sb}_{12}$. Phys. Rev. B 83, 024511 (2011).

96. Nicklas, M., Kirchner, S., Borth, R., Gumeniuk, R., Schnelle, W., Rosner, H., Borrmann, H., Leithe-Jasper, A., Grin, Yu., Steglich, F. Charge-Doping-Driven Evolution of Magnetism and Non-Fermi-Liquid Behavior in the Filled Skutterudite $\mathrm{CePt}_{4} \mathrm{Ge}_{12-x} \mathrm{Sb}_{x}$. Phys. Rev. Lett. 109, 236405 (2012).

97. Mandrus, D., Migliori, A., Darling, T. W., Hundley, M. F., Peterson, E. J., Thompson, J. D. Electronic transport in lightly doped CoSb3. Phys. Rev. B 52, 4926-4931 (1995).

98. Singh, D. J., Pickett, W. E. Skutterudite antimonides: Quasilinear bands and unusual transport. Phys. Rev. B 50, 11235-11238 (1994).

99. Dyck, J. S., Chen, W., Yang, J., Meisner, G. P., Uher, C. Effect of Ni on the transport and magnetic properties of $\mathrm{Co}_{1-x} \mathrm{Ni}_{x} \mathrm{Sb}_{3}$. Phys. Rev. B 65, 115204 (2002). 
100. Wan, S., Huang, X., Qiu, P., Shi, X., Chen, L. Compound defects and thermoelectric properties of self-charge compensated skutterudites $\mathrm{Se}_{y} \mathrm{Co}_{4} \mathrm{Sb}_{12-x} \mathrm{Se}_{x}$. ACS Appl. Mater. Interfaces 9, 22713-22724 (2017).

101. Zhang, J., Xu, B., Wang, L.-M., Yu, D., Liu, Z., He, J., Tian, Y. Great thermoelectric power factor enhancement of $\mathrm{CoSb}_{3}$ through the lightest metal element filling. Appl. Phys. Lett. 98, 072109 (2011).

102. Pei, Y. Z., Yang, J., Chen, L. D., Zhang, W., Salvador, J. R., Yang, J. Improving thermoelectric performance of caged compounds through light-element filling. Appl. Phys. Lett. 95, 042101 (2009).

103. Pei, Y. Z., Chen, L. D., Zhang, W., Shi, X., Bai, S. Q., Zhao, X. Y., Mei, Z. G., Li, X. Y. Synthesis and thermoelectric properties of $\mathrm{K}_{y} \mathrm{Co}_{4} \mathrm{Sb}_{12}$. Appl. Phys. Lett. 89, 221107 (2006).

104. Yang, J., Zhang, L., Liu, Y., Chen, C., Li, J., Yu, D., He, J., Liu, Z., Tian, Y., Xu, B. Investigation of skutterudite $\mathrm{Mg}_{y} \mathrm{Co}_{4} \mathrm{Sb}_{12}$ : High pressure synthesis and thermoelectric properties. J. Appl. Phys. 113, 113703 (2013).

105. Puyet, M., Lenoir, B., Dauscher, A., Dehmas, M., Stiewe, C., Müller, E. High temperature transport properties of partially filled $\mathrm{Ca}_{x} \mathrm{Co}_{4} \mathrm{Sb}_{12}$ skutterudites. J. Appl. Phys. 95, 4852-4855 (2004).

106. Chen, L. D., Kawahara, T., Tang, X. F., Goto, T., Hirai, T., Dyck, J. S., Chen, W., Uher, C. Anomalous barium filling fraction and n-type thermoelectric performance of $\mathrm{Ba}_{y} \mathrm{Co}_{4} \mathrm{Sb}_{12}$. J. Appl. Phys. 90, 1864-1868 (2001).

107. Zhao, X. Y., Shi, X., Chen, L. D., Zhang, W. Q., Zhang, W. B., Pei, Y. Z. Synthesis and thermoelectric properties of Sr-filled skutterudite $\mathrm{Sr}_{y} \mathrm{Co}_{4} \mathrm{Sb}_{12}$. J. Appl. Phys. 99, 053711 (2006). 108. Mi, J.-L., Christensen, M., Nishibori, E., Kuznetsov, V., Rowe, D. M., Iversen, B. B. Multitemperature synchrotron powder diffraction and thermoelectric properties of the skutterudite $\mathrm{La}_{0.1} \mathrm{Co}_{4} \mathrm{Sb}_{12}$. J. Appl. Phys. 107, 113507 (2010).

109. Qiu, P., Shi, X., Giu, Y., Huang, X., Wan, S., Zhang, W., Chen, L., Yang, J. Enhance ment 
of thermoelectric performance in slightly charge-compensated $\mathrm{Ce}_{y} \mathrm{Co}_{4} \mathrm{Sb}_{12}$ skutterudites. Appl. Phys. Lett. 103, 062103 (2013).

110. Nolas, G. S., Kaeser, M., Littleton IV, R. T., Tritt, T. M. High figure of merit in partially filled ytterbium skutterudite materials. Appl. Phys. Lett. 77, 1855-1857 (2000).

111. Pei, Y. Z., Bai, S. Q., Zhao, X. Y., Zhang, W., Chen, L. D. Thermoelectric properties of $\mathrm{Eu}_{y} \mathrm{Co}_{4} \mathrm{Sb}_{12}$ filled skutterudites. Solid State Sci. 10, 1422-1428 (2008).

112. Sales, B. C., Chakoumakos, B. C., Mandrus, D. Thermoelectric properties of thalliumfilled skutterudites. Phys. Rev. B 61, 2475-2481 (2000).

113. Qiu, Y., Xi, L., Shi, X., Qiu, P., Zhang, W., Chen, L., Salvador, J. R., Cho, J. Y., Yang, J., Chien, Y.-C., Chen, S.-W., Tang, Y., Snyder, G. J. Charge-Compensated Compound Defects in Ga-containing Thermoelectric Skutterudites. Adv. Funct. Mater. 23, 3194-3203 (2013).

114. He, T., Chen, J., Rosenfeld, H. D., Subramanian, M. A., Chem. Mater. 18, 759-762 (2006). 115. Duan, B., Yang, J., Salvador, J. R., He, Y., Zhao, B., Wang, S., Wei, P., Ohuchi, F., Zhang, W., Hermann, R. P., Gourdon, O., Mao, S. X., Cheng, Y., Wang, C., Liu, J., Zhai, P., Tang, X., Zhang, Q., Yang, J. Electronegative guests in CoSb3. Energy Environ Sci. 9, 2090-2098 (2016). 116. Ortiz, B. R., Crawford, C. M., McKinney, R. W., Parilla, P. A., Toberer, E. S. Thermoelectric properties of bromine filled $\mathrm{CoSb}_{3}$ skutterudite. J. Mater. Chem. A 4, 84448450 (2016).

117. Li, J. L., Duan, B, Yang, H. J., Wang, H., Li, G., Yang, J., Chen, G., Zhai, P. Thermoelectric properties of electronegatively filled $\mathrm{S}_{y} \mathrm{Co}_{4}-x \mathrm{Ni}_{x} \mathrm{Sb}_{12}$ skutterudites. J. Mater. Chem. C 7, 8079-8085 (2019).

118. Liu, Z.-Y., Zhu, J.-L., Tong, X., Niu, S., Zhao, W.-Y. A review of $\mathrm{CoSb}_{3}$-based skutterudite thermoelectric materials. J. Adv. Ceramics 9, 647-673 (2020).

119. Koza, M. M. Johnson, M. R., Viennois, R., Mutka, H., Girard, L., Ravot, D. Breakdown of phonon glass paradigm in La- and Ce-filled $\mathrm{Fe}_{4} \mathrm{Sb}_{12}$ skutterudites. Nature Mat. 7, 805-810 (2008). 
120. Alleno, E., Benyahia, M., Vaney, J.-B., Provost, K., Paul-Boncour, V., Monnier, J., Dauscher, A., Lenoir, B. High thermoelectric figure of merit in well optimized $\mathrm{Yb}_{y} \mathrm{Co}_{4} \mathrm{Sb}_{12}$. J. Mater. Chem. C 8, 17034-17044 (2020).

121. Tang, Y., Hanus, R., Chen, S.-W., Snyder, G. J. Solubility design leading to high figure of merit in low-cost Ce-CoSb3 skutterudites. Nat. Commun. 6, 7584 (2015).

122. Tang, Y., Qiu, Y., Xi, L., Shi, X., Zhang, W., Chen, L., Tseng, S.-M. Chen, S.-W., Snyder, G. J. Phase diagram of $\mathrm{In}-\mathrm{Co}-\mathrm{Sb}$ system and thermoelectric properties of In-containing skutterudites. Energy Environ. Sci. 7, 812-819 (2014).

123. Sales, B. C., Mandrus, D., Williams, R. K. Filled skutterudite antimonides: a new class of thermoelectric materials. Science 272, 1325-1328(1996).

124. Luo, H., Krizan, J. W., Muechler, L., Haldolaarachchige, N., Klimczuk, T., Xie, W., Fuccillo, M. K., Felser, C., Cava, R. J. A large family of filled skutterudites stabilized by electron count. Nat. Commun. 6, 6489 (2015).

125. Jeitschko, W., Braun, D. J. LaFe4P12 with filled CoAs type structure and isotypic $\operatorname{Ln}_{x} \mathrm{M}_{y} \mathrm{P}_{z}$. Acta Cryst. 33, 3401 (1977).

126. Morelli, D. T., Meisner, G. P., Chen, B., Hu, S., Uher, C. Cerium filling and doping of cobalt triantimonide. Phys. Rev. B 56, 7376-7383 (1997).

127. Zhang, Q. H., Huang, X. Y., Bai, S. Q., Shi, X., Uher, C., Chen, L. D. Thermoelectric Devices for Power Generation: Recent Progress and Future Challenges. Adv. Eng. Mater. 18, 194-213 (2016).

128. He, R., Schierning, G., Nielsch, K. Thermoelectric devices: A review of devices, architectures and contact optimization. Adv. Mater. Technol. 3, 1700256 (2018).

129. Chu, J., Huang, J., Liu, R., Liao, J., Xia, X., Zhang, Q., Wang, C., Gu, M., Bai, S. Q., Shi, X., Chen, L. D. Nat. Commun. 11, 2723 (2020).

130. Caillat, T., Chi, I., Huang, C.-K., Smith, K., Yu, K., Paik, J., Gogna, P., Phan, B., Heian, E., Holgate, T., VanderVeer, J., Bennett, R., Keyser, S., Frye, P., Wefers, K., Hoffmann, M., 
Deminico, M. An update of skutterudite-based thermoelectric technology for integration into a potential enhanced multi-mission radioisotope thermoelectric generator (eMMRTG). Nuclear and Emerging Technologies for Space, Knoxville, USA, 2020. Available online at https://nets2020.ornl.gov.

131. Toberer, E. S., May, A. F., Snyder, G. J. Zintl Chemistry for Designing High Efficiency Thermoelectric Materials. Chem. Mater. 22, 624-634 (2010).

132. Peng, W., Chanakian, S., Zevalkink, A. Crystal chemistry and thermoelectric transport of layered $\mathrm{AM}_{2} \mathrm{X}_{2}$ compounds. Inorg. Chem. Front. 5, 1744-1759 (2018).

133. Shuai, J., Mao, J., Song, S., Zhang, Q., Chen, G., Ren, Z. Recent progress and future challenges on thermoelectric Zintl materials. Mater. Today Phys. 1, 74-95 (2017).

134. Kauzlarich, S. M., Brown, S. R., Snyder, G. J. Zintl phases for thermoelectric devices. Dalton Trans. 2099-2107 (2007).

135. Chanakian, S., Aydemir, U., Zevalkink, A., Gibbs, Z. M., Fleurial, J.-P., Bux, S., Snyder, G. J. High temperature thermoelectric properties of $\mathrm{Zn}$-doped $\mathrm{Eu}_{5} \mathrm{In}_{2} \mathrm{Sb}_{6}$. J. Mater. Chem. C 3, $10518-10524(2015)$.

136. Ohno, S., Zevalkink, A., Takagiwa, Y., Bux, S. K., Snyder, G. J. Thermoelectric properties of the $\mathrm{Yb}_{9} \mathrm{Mn}_{4.2-x} \mathrm{Zn}_{x} \mathrm{Sb}_{9}$ solid solutions. J. Mater. Chem. A 2, 7478-7483 (2014).

137. Pomrehn, G. S., Zevalkink, A., Zeier, W. G., Van De Walle, A., Snyder, G. J. Defectcontrolled electronic properties in $A \mathrm{Zn}_{2} \mathrm{Sb}_{2}$ Zintl phases. Angewand. Chem. 53, 3422-3426 (2014).

138. Toberer, E. S., Brown, S. R., Ikeda, T., Kauzlarich, S., Snyder, G. J. High thermoelectric efficiency in lanthanum doped $\mathrm{Yb}_{14} \mathrm{MnSb}_{11}$. Appl. Phys. Lett. 93, 062110 (2008).

139. Yu, C., Chen, Y., Xie, H., Snyder, G. J., Fu, C., Xu, J., Zhao, X., Zhu, T. Improved Thermoelectric Properties in Lu-doped $\mathrm{Yb}_{14} \mathrm{MnSb}_{11}$ Zintl Compounds. Appl. Phys. Exp. 5, 031801 (2012).

140. Brown, S. R., Toberer, E. S., Ikeda, T., Cox, C. A., Gascoin, F., Kauzlarich, S. M., Snyder, 
G. J. Improved Thermoelectric Performance in $\mathrm{Yb}_{14} \mathrm{Mn}_{1-x} \mathrm{Zn}_{x} \mathrm{Sb}_{11}$ by the Reduction of SpinDisorder Scattering. Chem. Mater. 20, 3412-3419 (2008).

141. Möchel, A., Sergueev, I., Wille, H.-C., Juranyi, F., Schober, H., Schweika, W., Brown, S. R., Kauzlarich, S. M., Hermann, R. P. Lattice dynamics in the thermoelectric Zintl compound Yb14MnSb 11 . Phys. Rev. B 84, 184303 (2011).

142. Ravi, V., Firdosy, S., Caillat, T., Brandon, E., Van Der Walde, K., Maricic, L., Sayir, A. Thermal Expansion Studies of Selected High-Temperature Thermoelectric Materials. J. Electron. Mater. 38, 1433-1442 (2009).

143. Gorai, P., Goyal, A., Toberer, E. S., Stevanovic, V. A simple chemical guide for finding novel $n$-type dopable Zintl pnictide thermoelectric materials. J. Mater. Chem. A 7, 1938519395 (2019).

144. Ortiz, B. R., Gorai, P., Stevanovic, V., Toberer, E. S. Thermoelectric Performance and Defect Chemistry in $n$-Type Zintl $\mathrm{KGaSb}_{4}$. Chem. Mater. 29, 4523-4534 (2017).

145. Ortiz, B. R., Gorai, P., Krishna, L., Mow, R., Lopez, A., McKinney, R., Stevanovic, V., Toberer, E. S. Potential for high thermoelectric performance in $n$-type Zintl compounds: a case study of Ba doped KAlSb4. J. Mater. Chem. A 5, 4036-4046 (2017).

146. Tamaki, H., Sato, H. K., Kanno, T. Isotropic Conduction Network and Defect Chemistry in $\mathrm{Mg}_{3+\delta} \mathrm{Sb}_{2}$-Based Layered Zintl Compounds with High Thermoelectric Performance. Adv. Mater. 28, 10182-10187 (2016).

147. Zhang, J., Song, L., Pedersen, S. H., Yin, H., Hung, L. T., Iversen, B. B. Discovery of high-performance low-cost $n$-type $\mathrm{Mg}_{3} \mathrm{Sb}_{2}$-based thermoelectric materials with multi-valley conduction bands. Nat. Comm. 8, 13901 (2017).

148. Zhang, J., Song, L., Borup, K. A., Jorgensen, M. R. V., Iversen, B. B. New Insight on Tuning Electrical Transport Properties via Chalcogen Doping in $n$-type $\mathrm{Mg}_{3} \mathrm{Sb}_{2}$-Based Thermoelectric Materials. Adv. Energy Mater. 8, 1702776 (2018).

149. Shuai, J., Ge, B., Mao, J., Song, S., Wang, Y., Ren, Z. Significant Role of Mg 
Stoichiometry in Designing High Thermoelectric Performance for $\operatorname{Mg}_{3}(\mathrm{Sb}, \mathrm{Bi})_{2}$-Based $n$-Type Zintls. J. Am. Chem. Soc. 140, 1910-1915 (2018).

150. Imasato, K., Fu, C., Pan, Y., Wood, M., Kuo, J. J., Felser, C., Snyder, G. J. Metallic nType $\mathrm{Mg}_{3} \mathrm{Sb}_{2}$ Single Crystals Demonstrate the Absence of Ionized Impurity Scattering and Enhanced Thermoelectric Performance. Adv. Mater. 32, 1908218 (2020).

151. Pan, Y., Yao, M., Hong, X., Zhu, Y., Fan, F., Imasato, K., He, Y., Hess, C., Fink, J., Yang, J., Büchner, B., Fu, C., Snyder, G. J., Felser, C. $\mathrm{Mg}_{3}(\mathrm{Bi}, \mathrm{Sb})_{2}$ single crystals towards high thermoelectric performance. Energy Environ. Sci. 13, 1717-1724 (2020).

152. Imasato, K., Kang, S. D., Ohno, S., Snyder, G. J. Band engineering in $\mathrm{Mg}_{3} \mathrm{Sb}_{2}$ by alloying with $\mathrm{Mg}_{3} \mathrm{Bi}_{2}$ for enhanced thermoelectric performance. Mater. Horiz. 5, 59-64 (2018).

153. Mao, J., Zhu, H., Ding, Z., Liu, Z., Gamage, G. A., Chen, G., Ren, Z. High thermoelectric cooling performance of n-type $\mathrm{Mg}_{3} \mathrm{Bi}_{2}$-based materials. Science 365, 495-498 (2019).

154. Zhang, J., Iversen, B. B. Fermi surface complexity, effective mass, and conduction band alignment in $n$-type thermoelectric $\mathrm{Mg}_{3} \mathrm{Sb}_{2-x} \mathrm{Bi}_{x}$ from first principles calculations. J. Appl. Phys. 126, 085104 (2019).

155. Potel, M., Chevrel, R., Sergent, M. $\operatorname{In}_{2} \mathrm{Mo}_{15} \mathrm{Se}_{19}$ : nouvel exemple de structure à motifs $\mathrm{Mo}_{6} \mathrm{Se}_{8}$ et $\mathrm{Mog}_{9} \mathrm{Se}_{11}$. Acta Cryst. B37, 1007-1010 (1981).

156. Picard, S., Gougeon, P., Potel, M. $\mathrm{K}_{2} \mathrm{Mo}_{15} \mathrm{~S}_{19}$ :a novel ternary reduced molybdenum sulfide containing Mo6 and Mo9 clusters. Acta Cryst. E58, i12-i14 (2002).

157. Picard, S., Salloum, D., Gougeon, P., Potel, M. Cs2 Mo15S S19: a novel ternary reduced molybdenum sulfide containing Mo6 and Mog clusters. Acta Cryst. C60, i61-i62 (2004).

158. Gougeon, P., Gall, P., Al Rahal Al Orabi, R., Fontaine, B., Gautier, R., Potel, M., Zhou, T., Lenoir, B., Colin, M., Candolfi, C., Dauscher, A. Synthesis, Crystal and Electronic Structures, and Thermoelectric Properties of the Novel Cluster Compound $\mathrm{Ag}_{3} \operatorname{In}_{2} \mathrm{Mo}_{15} \mathrm{Se}_{19}$. Chem. Mater. 24, 2899-2908 (2012). 
159. Zhou, T., Colin, M., Candolfi, C., Boulanger, C., Dauscher, A., Santava, E., Hejtmanek, J., Baranek, P., Al Rahal Al Orabi, R., Potel, M., Fontaine, B., Gougeon, P., Gautier, R., Leno ir, B. Comprehensive Study of the Low-Temperature Transport and Thermodynamic Properties of the Cluster Compounds $\mathrm{Ag}_{x} \mathrm{Mog}_{9} \mathrm{Se}_{11}(3.41 \leq x \leq 3.78)$. Chem. Mater. 26, 4765-4775 (2014). 160. Al Rahal Al Orabi, R., Gougeon, P., Gall, P., Fontaine, B., Gautier, R., Colin, M., Candolfi, C., Dauscher, A., Hejtmanek, J., Malaman, B., Lenoir, B. X-ray characterization, electronic band structure, and thermoelectric properties of the cluster compound $\mathrm{Ag}_{2} \mathrm{Tl}_{2} \mathrm{Mog}_{9} \mathrm{Se}_{11}$. Inorg. Chem. 53, 11699-11709 (2014).

161. Al Rahal Al Orabi, R., Fontaine, B., Gautier, R., Gougeon, P., Gall, P., Bouyrie, Y., Dauscher, A., Candolfi, C., Lenoir, B. $\mathrm{Cu}$ Insertion Into the Mo12 Cluster Compound $\mathrm{Cs}_{2} \mathrm{Mo}_{12} \mathrm{Se}_{14}$ : Synthesis, Crystal and Electronic Structures, and Physical Properties. Inorg. Chem. 55, 6616-6624 (2016).

162. Gougeon, P., Gall, P., Merdrignac-Conanec, O., Aranda, L., Dauscher, A., Candolfi, C., Lenoir, B. Synthesis, Crystal Structure, and Transport Properties of the Hexagonal Mog Cluster Compound $\mathrm{Ag}_{3} \mathrm{RbMog}_{9} \mathrm{Se}_{11}$. Inorg. Chem. 56, 9684-9692 (2017).

163. Gougeon, P., Gall, P., Al Rahal Al Orabi, R., Boucher, B., Fontaine, B., Dauscher, A., Candolfi, C., Lenoir, B. Electronic Band Structure and Transport Properties of the Cluster Compound $\mathrm{Ag}_{3} \mathrm{Tl}_{2} \mathrm{Mo}_{15} \mathrm{Se}_{19}$. Inorg. Chem. 58, 5533-5542 (2019).

164. Al Rahal Al Orabi, R., Boucher, B., Fontaine, B., Gall, P., Candolfi, C., Lenoir, B., Gougeon, P., Halet, J.-F., Gautier, R. Towards the prediction of the transport properties of cluster-based molybdenum chalcogenides. J. Mater. Chem. C 5, 12097-12104 (2017).

165. Masschelein, P., Candolfi, C., Dauscher, A., Gendarme, C., Al Rahal Al Orabi, R., Gougeon, P., Potel, M., Gall, P., Gautier, R., Lenoir, B. Influence of S and Te substitutions on the thermoelectric properties of the cluster compound $\mathrm{Ag}_{3.8 \mathrm{M}} \mathrm{MoS}_{911}$. J. Alloys Compnd 739, 360-367 (2018). 
166. Daigre, G., Gougeon, P., Gall, P., Merdrignac-Conanec, O., Al Rahal Al Orabi, R., Gautier, R., Dauscher, A., Candolfi, C., Lenoir, B. Unravelling the Beneficial Influence of Ag insertion on the Thermoelectric Properties of the Cluster Compound $\mathrm{K}_{2} \mathrm{Mo}_{15} \mathrm{Se}_{19}$. ACS Appl. Ener. Mater. 3, 2846-2855 (2020).

167. Colin, M., Zhou, T., Lenoir, B., Dauscher, A., Al Rahal Al Orabi, R., Gougeon, P., Potel, M., Baranek, P., Semprimoschnig, C. Optimization of Bulk Thermoelectrics: Influence of Cu Insertion in $\mathrm{Ag}_{3.6} \mathrm{Mog}_{9} \mathrm{Se}_{11}$. J. Electron. Mater. 41, 1360-1364 (2012).

168. Butorin, S. M., Kvashnina, K. O., Klintenberg, M., Kavcic, M., Zitnik, M., Bucar, K., Gougeon, P., Gall, P., Candolfi, C., Lenoir, B. Effect of Ag Doping on Electronic Structure of Cluster Compounds $\mathrm{Ag}_{x} \mathrm{Mog}_{9} \mathrm{Se}_{11}(x=3.4,3.9)$. ACS Appl. Ener. Mater. 1, 4032-4039 (2018). 169. Zhou, T., Lenoir, B., Colin, M., Dauscher, A., Al Rahal Al Orabi, R., Gougeon, P., Potel, M., Guilmeau, E. Promising thermoelectric properties in $\mathrm{Ag}_{x} \mathrm{Mog}_{9} \mathrm{Se}_{11}$ compounds $(3.4 \leq x \leq$ 3.9). Appl. Phys. Lett. 98, 162106 (2011).

170. Candolfi, C., Misek, M., Gougeon, P., Al Rahal Al Orabi, R., Gall, P., Gautier, R., Migot, S., Ghanbaja, J., Kastil, J., Levinsky, P., Hejtmanek, J., Dauscher, A., Malaman, B., Lenoir, B. Coexistence of a charge density wave and superconductivity in the cluster compound K2Mo15Se19. Phys. Rev. B 101, 134521 (2020).

171. C. K. Poole, H. A. Farach, and R. J. Creswick, Handbook of Superconductivity (Academic, New York, 2000).

172. Aswal, D. K., Basu, R., Singh, A. Key issues in development of thermoelectric power generators: High figure-of-merit materials and their highly conducting interfaces with metallic interconnects. Energy Convers. Manag. 114, 50-67 (2016).

173. Freer, R., Powell, A. V. Realising the potential of thermoelectric technology: a Roadmap. J. Mater. Chem. C 8, 441-463 (2020). 
174. Mesalam, R., Williams, H. R., Ambrosi, R. M., Garcia-Canadas, J., Stephenson, K. Towards a comprehensive model for characterising and assessing thermoelectric modules by impedance spectroscopy. Appl. Energy 226, 1208-1218 (2018).

175. Mesalam, R., Williams, H. R., Ambrosi, R. M., Kramer, D. P., Barklay, C. D., GarciaCanadas, J., Stephenson, K., Weston, D. P. Impedance spectroscopy characterization of neutron irradiated thermoelectric modules for space nuclear power. AIP Advances 9, 055006 (2019). 